\title{
Long-run restrictions and survey forecasts of output, consumption and investment
}

Article

Accepted Version

Clements, M. P. (2016) Long-run restrictions and survey forecasts of output, consumption and investment. International Journal of Forecasting, 32 (3). pp. 614-628. ISSN 0169-2070 doi: https://doi.org/10.1016/j.ijforecast.2015.10.005 Available at https://centaur.reading.ac.uk/45303/

It is advisable to refer to the publisher's version if you intend to cite from the work. See Guidance on citing.

To link to this article DOI: http://dx.doi.org/10.1016/j.ijforecast.2015.10.005

Publisher: Elsevier

All outputs in CentAUR are protected by Intellectual Property Rights law, including copyright law. Copyright and IPR is retained by the creators or other copyright holders. Terms and conditions for use of this material are defined in the End User Agreement.

\section{www.reading.ac.uk/centaur}

\section{CentAUR}

Central Archive at the University of Reading

Reading's research outputs online 


\title{
Long-Run Restrictions and Survey Forecasts of Output, Consumption and Investment
}

\author{
Michael P. Clements* \\ ICMA Centre, \\ Henley Business School, \\ University of Reading, \\ Reading RG6 6BA
}

October 22, 2015

\begin{abstract}
We consider the extent to which long-horizon survey forecasts of consumption, investment and output growth are consistent with theory-based steady-state values, and whether imposing these restrictions on long-horizon forecasts will enhance their accuracy. The restrictions we impose are consistent with a two-sector model in which the variables grow at different rates in steady state. The restrictions are imposed by exponential-tilting of simple auxiliary forecast densities. We show that imposing the consumption-output restriction yields modest improvements in the long-horizon output growth forecasts, and larger improvements in the forecasts of the cointegrating combination of consumption and output: the transformation of the data on which accuracy is assessed plays an important role.
\end{abstract}

\footnotetext{
${ }^{*}$ Michael Clements is Professor of Econometrics at the ICMA Centre, Henley Business School, University of Reading, and an associate member of the Institute for New Economic Thinking at the Oxford Martin School, University of Oxford. Email: m.p.clements@reading.ac.uk. I am grateful to David Hendry for helpful comments, and to participants at the Reading University joint ICMA Centre and Economics Department Seminar. Helpful comments from an Associate Editor and Reviewer for this journal are also acknowledged.
} 


\title{
Long-Run Restrictions and Survey Forecasts of Output, Consumption and Investment
}

\begin{abstract}
We consider the extent to which long-horizon survey forecasts of consumption, investment and output growth are consistent with theory-based steady-state values, and whether imposing these restrictions on long-horizon forecasts will enhance their accuracy. The restrictions we impose are consistent with a two-sector model in which the variables grow at different rates in steady state. The restrictions are imposed by exponential-tilting of simple auxiliary forecast densities. We show that imposing the consumption-output restriction yields modest improvements in the long-horizon output growth forecasts, and larger improvements in the forecasts of the cointegrating combination of consumption and output: the transformation of the data on which accuracy is assessed plays an important role.
\end{abstract}




\section{Introduction}

We are interested in how forecasters forecast: whether survey expectations are informed by equilibrium conditions. Forecasters may not produce 'optimal' forecast paths of the future values of economic variables, ${ }^{1}$ but nevertheless consider the possibility that their long-horizon forecasts are informed by, and consistent with, the postulates of broad classes of economic theory, such as the existence of the balanced growth paths (of the Solow-Ramsey model) and the 'great ratios' of Kosobud and Klein (1961), or two-sector models (such as, e.g., Whelan (2003)) which predict that the key NIPA aggregates grow at different (constant) rates in the long run. Hence our focus is on whether professional forecasters are guided by equilibrium relationships when they forecast. Equilibrium relationships have played a prominent role in terms of the econometric modelling of dynamic relationships, especially following the coupling of error-correction and cointegration, ${ }^{2}$ and underpin DSGE modelling (see, e.g., Del Negro and Schorfheide (2013) for a recent review).

Our initial focus is on the so-called 'great ratios', as analyzed by King, Plosser, Stock and Watson (1991). They establish that the (natural) logs of the ratios of consumption to output, and of investment to output, constitute cointegrating combinations of these US macroeconomic variables in the post WWII period up to the end of their sample (1990). However, as argued by Whelan (2003), the one-sector balanced growth path model that implies the great ratios are stationary provides a poor fit to the US experience over the last quarter of a century, and the equilibrium relationships are amended accordingly.

Our proposal is to make use of the literature on imposing moment restrictions on models' forecast densities to impose restrictions on survey forecasts. The application of moment restrictions to survey forecasts is a novel feature of this paper. The existing literature takes a model forecast density, say, $f_{t}\left(x_{t+h}\right)$, and seeks a new density, in the class of densities which satisfy

\footnotetext{
${ }^{1}$ The influential study by Keane and Runkle (1990) fails to reject the Rational Expectations Hypothesis $(\mathrm{REH})$, but there is overwhelming evidence against the REH (see, e.g., the studies listed by Branch (2004, p. 592)). As a consequence, there has been much interest in the notion of 'bounded rationality', which makes less stringent informational and computational requirements of agents: given costs of information acquisition and processing, it may be rational not to be a rational-expectations forecaster (see Evans and Ramey (1992), Sargent (1993), inter alia, for early contributions, Evans and Honkapohja (2001), and Hommes (2006) for a recent survey).

${ }^{2}$ The first paper to bring 'error-correction' to the economics literature was Sargan (1964), with Davidson, Hendry, Srba and Yeo (1978) being especially influential, whilst Engle and Granger (1987) is a key paper on cointegration.
} 
the moment restrictions, which is closest to the original in an information-theoretic sense. That is, a density which minimizes the relative entropy between the new and original distributions. The methods were proposed as a means of incorporating restrictions on the forecasts of models without the need to impose such restrictions directly on the model itself. ${ }^{3}$

Once we consider survey forecasts there is no option but to impose the required restrictions directly on the survey forecasts, given that the model used to generate the expectations is unknown. Nevertheless, as we describe in section 4, the imposition of moment restrictions on survey forecasts will require that we (as the econometrician) model the dependencies between the forecasts in order to impose the restrictions on the point forecasts. That is, in the absence of a model that generates the forecast density, we will need to estimate an auxiliary forecast density based on past survey forecast errors. These densities are not of interest in themselves, but are instrumental in generating the tilted point forecasts. Thus we subsequently consider the tilted point forecasts and the reported point forecasts (rather than the tilted and un-tilted densities. $^{4}$ )

Why might one wish to impose restrictions on survey forecasts, rather than imposing restrictions on model forecasts (as in e.g., Smets, Warne and Wouters (2014))? Relative to models, surveys potentially use vast amounts of information, including the effects of one-off events and idiosyncratic factors, all of which are tempered by the survey respondent's judgement and expertise. ${ }^{5}$ As an example of the perceived quality of survey forecasts, Wright (2013) suggests shrinking the unconditional means of the series in a VAR to survey long-horizon forecasts. We ask instead whether the long-horizon forecasts are themselves amenable to improvement by the imposition of economically-meaningful restrictions. In so doing we consider the extent to which

\footnotetext{
${ }^{3}$ For example, Robertson, Tallman and Whiteman (2005) use these procedures to produce forecasts - which embody theoretically coherent structural restrictions - from macroeconometric models. Altavilla, Giacomini and Ragusa (2014) use the technique to 'anchor' short-end model estimates of the yield curve to survey expectations, and Giacomini and Ragusa (2014) offer an application whereby Euler equation restrictions are imposed on Bayesian vector autoregressions.

${ }^{4}$ A number of studies that impose moment restrictions on model forecasts evaluate the tilted density forecasts as well as the point predictions. For example, Giacomini and Ragusa (2014) derive the result that the sense in which imposing true (in population) moment conditions will improve out-of-sample forecasting is in terms of providing weakly more accurate density forecasts when accuracy is measured by the logarithmic scoring rule.

${ }^{5}$ For example Zarnowitz and Braun (1993, p. 23) report that participants 'use a variety of procedures to predict the major expenditure components of GNP, combine these predictions in nominal and real terms, and check and adjust the resulting forecasts for consistency with logic, theory, and the currently available information'. See also Batchelor and Dua (1991) inter alia.
} 
the survey forecasts already embody these restrictions. If they do, then the restricted survey forecasts will of course simply reproduce the survey forecasts.

To anticipate our findings: if we look at the forecasts of growth rates, it appears that the professional forecasters do already incorporate the two-sector growth model cointegrating relationships, in that there is no statistical difference in forecast accuracy between the reported forecasts, and the forecasts with the implied restrictions imposed. Moreover, we are unable to reject the null hypotheses that each set of forecasts contains all the useful information in the other set of forecasts. However, it may well be that the cointegrating restrictions have only a relatively small effect on the forecasts of the growth rates, so that their influence is largely undetectable. When we analyze the accuracy of the forecasts of the cointegrating combinations of the variables themselves, we find that imposing the long-run restrictions does have an appreciable effect. There is a statistically significant loss in accuracy from imposing the restrictions for forecasting the investment/output levels combination, with the reverse finding in terms of the consumption/output levels combination.

The plan of the rest of the paper is as follows. Section 2 describes the imposition of moment restrictions on models' forecasts, and how we adapt this to impose restrictions on long-horizon survey forecasts. Section 3 discusses the nature of the long-run restrictions we may wish to impose, and the appropriate way of evaluating forecasts of non-stationary (integrated) economic time-series variables when interest turns on the role of equilibrium features. Section 4 discusses how the moment restrictions are applied to the US Survey of Professional Forecasters (SPF) median forecasts of real GDP, consumption and investment, and section 5 records the results. Section 6 concludes.

\section{Moment restrictions and model forecasts}

Suppose that $f_{t}\left(x_{t+h}\right)$ is a multivariate density, $f_{t}\left(x_{t+h}\right) \sim D\left(\mu_{t+h}, \Sigma_{t+h}\right)$, where $x_{t+h}$ is a vector of $N$ elements. At the forecast origin $t$, we also have the moment restrictions $E_{t}\left[g\left(x_{t+h}-\widetilde{\mu}_{t+h}\right)\right]=$ 0 . We assume the existence of a new density $h_{t}\left(x_{t+h}\right)$ which satisfies the moment restrictions:

$$
\int g\left(x_{t+h}-\widetilde{\mu}_{t+h}\right) h_{t}\left(x_{t+h}\right) d x_{t+h}=0
$$


whereas:

$$
\int g\left(x_{t+h}-\widetilde{\mu}_{t+h}\right) f_{t}\left(x_{t+h}\right) d x_{t+h} \neq 0 .
$$

If we let $\widetilde{H}_{t+h}=\left\{h_{t}: \int g\left(x_{t+h}-\widetilde{\mu}_{t+h}\right) h_{t}\left(x_{t+h}\right) d x_{t+h}=0\right\}$ denote the set of densities which satisfy these restrictions, then the optimal $h_{t}, h_{t}^{*}$, which is closest to $f_{t}$ solves the minimization problem:

$$
h_{t}^{*}\left(x_{t+h}\right)=\underset{h_{t} \in \widetilde{H}_{t+h}}{\arg \min } \int \log \left(\frac{h_{t}(u)}{f_{t}(u)}\right) h_{t}(u) d u_{t}
$$

and takes the form:

$$
h_{t}^{*}\left(x_{t+h}\right)=\exp \left\{\eta_{t}+\xi_{t}^{\prime}\left[g\left(x_{t+h}-\tilde{\mu}_{t+h}\right)\right]\right\} f_{t}\left(x_{t+h}\right)
$$

where $\xi_{t}$ and $\eta_{t}$ are chosen such that $h_{t} \in \widetilde{H}_{t+h} \cdot{ }^{6}$

A standard case in the literature that permits an analytical solution is when $f_{t}()$ is multivariate normal, and $g$ is a selection matrix that picks out the first $n_{1}$ variables, say, so $g\left(x_{t+h}-\widetilde{\mu}_{t+h}\right)=x_{1: n_{1}, t+h}-\widetilde{\mu}_{1: n_{1}, t+h}$, where $x_{1: n_{1}, t+h}=\left(x_{1, t+h}, \ldots, x_{n_{1, t+h}}\right)^{\prime}$ and $\widetilde{\mu}_{1: n_{1}, t+h}=$ $\left(\widetilde{\mu}_{1, t+h}, \ldots, \widetilde{\mu}_{n_{1, t+h}}\right)$. Then the optimal tilted density $h$ is also multivariate normal (see Robertson et al. $\left.(2005)^{7}\right)$, with mean vector given by:

$$
\mu_{t+h}^{*}=\left[\begin{array}{c}
\widetilde{\mu}_{1: n_{1}, t+h} \\
\mu_{n_{1}+1: n, t+h}+\Sigma_{21, t+h}\left(\Sigma_{11, t+h}\right)^{-1}\left(\widetilde{\mu}_{1: n_{1}, t+h}-\mu_{1: n_{1}, t+h}\right)
\end{array}\right] .
$$

From the second row of (1) it is apparent that the restrictions on the first $n_{1}$ variables will also affect the remaining variables unless the two sets of variables are independent, which here requires that $\Sigma_{21, t+h}=0$.

The economically meaningful long-run restrictions we wish to impose are cross-variable restrictions on the long-horizon forecasts, for example, that the long-horizon forecasts of consumption and income growth are equal. This is an implication of the one-sector balanced growth path model. More generally, we require that the forecasts of the growth rates satisfy the coin-

\footnotetext{
${ }^{6}$ See Stutzer (1996), Kitamura and Stutzer (1997), Robertson et al. (2005), Giacomini and Ragusa (2014) and Altavilla et al. (2014), inter alia. Our brief summary draws on the last of these.

${ }^{7}$ Robertson et al. (2005) also present a Gaussian example with variance restrictions as well as mean restrictions.
} 
tegrating relations. If $\beta$ is the $N$ by $r$ matrix such that $\beta^{\prime} X_{t} \sim I(0)$ when $X_{t} \sim I(1)$, where $X_{t}$ denotes the levels of the variables, then we require that $\beta^{\prime} x_{t+h \mid t}=0$ for large $h$. The set of moment restrictions are then that $E_{t}\left[g\left(x_{t+h}-\widetilde{\mu}_{t+h}\right)\right]=0$ with $g\left(x_{t+h}-\widetilde{\mu}_{t+h}\right)=\beta^{\prime} x_{t+h}$. We assume a multivariate normal distribution for the vector of growth rates $x_{t+h}$. Then it is straightforward to show that the optimal tilted density is also multivariate normal, i.e., $h_{t}^{*}\left(x_{t+h}\right) \sim N\left(\mu_{t+h}^{*}, \Sigma_{t+h}\right)$. The variance-covariance matrix is the same as that of the original density $f$, and the tilted mean vector is given by:

$$
\mu_{t+h}^{*}=\mu_{t+h}-\Sigma_{t+h} \beta\left(\beta^{\prime} \Sigma_{t+h} \beta\right)^{-1} \beta^{\prime} \mu_{t+h} .
$$

The derivation of (2) is confined to Appendix A. It follows immediately that $\beta^{\prime} \mu_{t+h}^{*}=0$, as required. To gain some intuition, consider (2) when $N=2$ and $r=1$, and $\beta=(1,-1)^{\prime}$, and $\Sigma_{t+h}$ is diagonal. We obtain:

$$
\mu_{t+h}^{*}=\left[\begin{array}{c}
\left(\frac{\sigma_{22}}{\sigma_{11}+\sigma_{22}}\right) \mu_{1}+\left(\frac{\sigma_{11}}{\sigma_{11}+\sigma_{22}}\right) \mu_{2} \\
\left(\frac{\sigma_{22}}{\sigma_{11}+\sigma_{22}}\right) \mu_{1}+\left(\frac{\sigma_{11}}{\sigma_{11}+\sigma_{22}}\right) \mu_{2}
\end{array}\right]
$$

This yields the intuitively reasonable result that $\mu_{t+h}^{*}$ is a weighted average of $\left\{\mu_{1, t+h}, \mu_{2, t+h}\right\}$ where the weights reflect the relative variabilities of $x_{1, t+h}$ and $x_{2, t+h}$ such that if, say, $\sigma_{11} \gg$ $\sigma_{22}$, then $\mu_{t+h}^{*}$ will be closer to $\mu_{2, t+h}$ than $\mu_{1, t+h}$. Equation (2) holds for any $N, r(N>r$, $r>0)$ and for non-diagonal $\Sigma_{t+h}$.

Rather than imposing restrictions on the $h$-step forecasts independently, we can also jointly impose restrictions on (say) the $h-1$ and $h$-step ahead forecasts. To do so we assume the vector $x_{t+h}$ is now given by $x_{t+h}=\left(x_{1, t+h-1}, x_{2, h+h-1}, x_{1, t+h}, x_{2, t+h}\right)^{\prime}$ (when $N=2$ ) and is again MVN, so that $\Sigma_{t+h}$ is now of order 4 and includes covariances between the $t+h$ and $t+h-1$ variables. Equation (2) gives the tilted forecasts, where now $\mu_{t+h}=$ 
$\left(\mu_{2, t+h-1}, \mu_{2, t+h-1}, \mu_{1, t+h}, \mu_{2, t+h}\right)$, and $\beta$ is given by:

$$
\beta=\left[\begin{array}{cc}
1 & 0 \\
-1 & 0 \\
0 & 1 \\
0 & -1
\end{array}\right]
$$

when the restriction is of long-run proportionality.

\section{The long-run restrictions and Forecast evaluation}

Long-run relationships between economic variables impose restrictions on the optimal longhorizon forecasts of the growth rates of those variables (as shown in Appendix B). The balancedgrowth hypothesis implied by one-sector real-business-cycle models suggests that output, investment and consumption all grow at the same rate in steady state, and that the 'great ratios' are approximately constant over time (as in Kosobud and Klein (1961), for example). King et al. (1991) cast this in terms of the three variables being driven by a single common stochastic trend, and the (logs of) the consumption - output and investment - output ratios being integrated of order zero, I (0) (in the sense of Engle and Granger (1987)). King et al. (1991) found that the cointegration relationships implied by the great ratios held in the postwar US for their sample which ended in 1988. We find there is less empirical support for the great ratios hypothesis when the sample is extended to the present day, as noted by Whelan (2003). This latter period spans the period over which we assess the value of imposing long-run restrictions on survey forecasts. Figures 1 and 2 plot the natural logarithms of output, consumption and investment (defined in detail in section 4) and of the logs of the great ratios, i.e., the log of consumption minus the $\log$ of output, and the $\log$ of investment less the $\log$ of output. From Figure 1 the positive trend growth in all three series is apparent, as is the greater variability of investment relative to consumption, but figure 2 suggests there is less evidence that the log-ratios are $I(0)$ when the 1990's and 2000's are added (compared to King et al. (1991, Figure 1, p.825)). There is a prolonged boom in investment during the 1990's only ending with the Financial Crisis, such that mean-reversion would appear to be weaker than during the earlier period. Figure 3 reports 
recursive augmented Dickey-Fuller tests of the null that the great ratios are $I(1)$. While the unit root in the consumption-output ratio is rejected, there is evidence that the unit root is not rejected for the investment-output ratio when the sample period includes observations from the 2000's, consistent with the graphical analysis.

Whelan (2003) argues that a two-sector model provides a better description of the U.S. economy in the post WWII period, and that such a model suggests consumption, investment and output have different steady state growth rates. This is essentially because technical progress in the production of durable goods proceeds more rapidly than in non-durable goods, and because durable goods constitute a greater proportion of investment spending than consumption spending. Motivated by the two-sector model and the estimates provided by Whelan (2003, table 2, p.646), we assume that $\beta^{\prime}=(1,-0.95)$ when $x=(\ln \text { consumption, } \ln \text { output })^{\prime}$ and $\beta^{\prime}=(1,-1.35)$ when $x=(\text { ln investment, } \ln \text { output })^{\prime}$, capturing the faster steady-state growth of investment.

Finally, we adopt a data-based approach to the determination of the appropriate restrictions. At each forecast origin, we estimate the long-run relations using past data (observations and data-vintage) available at that time. This is fully discussed in section 5.4.

Finally, Clements and Hendry (1995) establish that the value of modelling long-run relationships will be most clearly evident in the forecasts of the cointegrating combinations of the variables, rather than in improved accuracy of the forecasts of their growth rates (see Appendix C for the key results). So if the survey forecasters do have equilibrium relationships in mind, the value of these may not be apparent if we calculate MSEs for the forecasts of the growth rates, as is standard practice. Hence a key focus will be on the reported and tilted forecasts of the cointegrating combinations of the levels of the variables.

\section{Empirical analysis of the effects of imposing long-run restric- tions on survey forecasts}

We use the US Survey of Professional Forecasters (SPF). The SPF is a quarterly survey of macroeconomic forecasters of the US economy that began in 1968, administered by the American Statistical Association (ASA) and the National Bureau of Economic Research (NBER). 
Since June 1990 it has been run by the Philadelphia Fed, renamed as the Survey of Professional Forecasters $(\mathrm{SPF}) .{ }^{8}$ We use the median point predictions of output, consumption and investment from the 1981:3 surveys onwards (see table 1). Following King et al. (1991) we use 'private' GNP (GDP) as the measure of output: this is GDP less the total government spending on consumption and investment. Forecasts are provided for the median forecasts of the levels and growth rates of these variables for the current survey quarter, and for the next four quarters, so that the longest horizon forecast is of the same quarter a year ahead. ${ }^{9}$

Our approach of applying long-run restrictions requires that the year ahead forecasts (effectively a five-quarter ahead forecast, as there is typically little information available on the current survey quarter) can be regarded as a reasonable approximation to long-horizon forecasts. We cannot show this is the case, but there is evidence to suggest it may be a reasonable assumption. Firstly, table 2 records the means and standard deviations for forecasts of the current quarter to the year ahead horizon. These statistics are calculated for all the surveys in our sample (1990:Q3 to 2012:Q2) and for a subset that excludes 2006:Q1 to 2012:Q2, that is, the recent Crisis period. Consider first the results for all the forecast origins (left side of the table). The estimates show that the average forecasts are virtually unchanged between the two longest horizons, $h=3$ and 4 , for all three variables. By way of contrast, the average longer horizon forecasts are very different from the average current quarter forecasts for output growth and investment. This suggests that by $h=3,4$ the influence of developments underway at the time the forecasts were made are having a minimal influence on the forecasts, as would be expected of 'long-horizon' forecasts. In addition, the standard deviations of the $h=4$ forecasts are generally around a third of the values for the current quarters. Further, the mean long-horizon forecasts are broadly the same if we exclude the turbulent end years of the sample, whereas the short horizon forecasts are not (e.g., the average current-quarter investment forecast falls from

\footnotetext{
${ }^{8}$ The early years of the survey are discussed by e.g., Zarnowitz (1969), Zarnowitz and Braun (1993) and Croushore (1993), and an academic bibliography of the large number of published papers that use SPF data is available at: http://www.phil.frb.org/research-and-data/real-time-center/survey-of-professionalforecasters/academic-bibliography.cfm

${ }^{9}$ Although the SPF provides forecasts of the levels of the variables, and percentage-change growth rates, we report results for growth rates calculated as differences of logs, and for cointegrating combinations of the log levels. This seems more natural within a cointegration framework.

The surveys provide forecasts of the current and next years' annual averages, in addition to forecasts of quarterly values, so for the early quarters in the year, it would be possible to construct (under some assumptions) forecasts of quarterly quantities beyond 5-quarters ahead.
} 
$1 \%$ to $\frac{3}{4} \%$ when the Crisis period is included), reinforcing the point that by $h=4$ the forecasts are largely insensitive to forecast origin events.

Secondly, since 2009:Q2 the SPF has invited respondents to give their forecasts of the annual level of output for 2 and 3 years in the future, relative to the survey quarter. ${ }^{10}$ So for a first quarter of the year forecast, these forecasts are effectively 12 and 16 quarters ahead, respectively, but the horizon is shorter for surveys later in the year. We use these forecasts as an additional check as to whether the $h=4$ forecasts can be regarded as 'long-horizon', notwithstanding the relatively short sample of forecasts, 2009:Q2 to 2013:4, and that such forecasts are only available for output. The mean of the forecasts of the annual percentage growth rate 3-years ahead was 3.04 with a standard deviation of 0.28 . We annualized the $h=4$ forecasts for comparability, and over the restricted sample period found a mean forecast of 2.86 and a standard deviation of 0.21 . This was taken as evidence that the $h=4$ forecasts were not very different from the 3 -year ahead forecasts, and that it might be reasonable to suppose that $h=4$ forecasts are a reasonable proxy for long-horizon forecasts. ${ }^{11}$

The SPF median forecasts of the growth rates of consumption, investment and output are depicted in figures 4 and 5. We present crossplots of the consumption and output forecast data, and of the investment and output forecast data, respectively, for the period 1981Q3 to 2013Q4, presenting the forecasts separately by forecast horizon. The forecast growth rates are clearly positively correlated at all horizons for consumption and output (figure 4) and investment and output (figure 5) as expected. It does not appear that the dispersion of the scatter diminishes markedly as the horizon increases, as would be anticipated if the quarterly growth rates were tied together more closely at $h=4$, say. Further, from figure 5 it is apparent that the fitted least-squares line is flatter than the 45-degree line for each $h$, indicating that forecast changes in investment on average exceed the corresponding forecasts of growth rates over the last two decades. That this is true of the $h=4$ proxy long-horizon forecasts suggests professional forecasters expectations are more in tune with the predictions of the two-sector model (unequal steady-state growth paths) than the one-sector model balanced growth paths.

\footnotetext{
${ }^{10}$ So for 2009:Q2 these forecasts are of the average level of output in 2011 and 2012.

${ }^{11}$ The SPF does provide 10-year ahead forecasts of CPI inflation from 1991:Q4 onwards, so that a formal assessment can be made of how well the 5-quarter forecasts approximate long-horizon (10-year ahead) forecasts for inflation: see Clements (2015). Although these two inflation expectations series are highly correlated, it is not clear whether the findings for inflation would carry over to real variables.
} 
We make use of the Real Time Data Set for Macroeconomists (RTDSM) maintained by the Federal Reserve Bank of Philadelphia (see Croushore and Stark (2001)) as a source of 'real-time' actual values against which the forecasts are compared. Specifically, we use as actual values the second-release quarterly vintage figures from the Croushore-Stark RTDSM. Using real-time actual values has become commonplace in the literature, as it seems inappropriate to use as actual values data released possibly many years later which include benchmark revisions and methodological changes to the way the statistics are collected.

The switch from a 'fixed-base-year' to chain-weighted estimates of real GDP and its components in the 1990's may potentially have an impact on our analysis, as with chain-weighting it is no longer true that the GDP components necessarily sum to GDP, or to intermediate subaggregates. Hence one might take issue over the calculation of private GDP, and the summing of the two investment components, because strictly-speaking these components are not summable. However, it seems likely that any resulting distortions will be of secondary importance.

The approach outlined in section 2 requires multivariate forecast densities. These are not provided by the SPF: instead we have point forecasts of the three variables of interest as described above. ${ }^{12}$ Our approach is to construct 'auxiliary' multivariate normal densities at each survey quarter, using the past forecast errors up to that point to estimate the MVN variance-covariance matrix. The mean forecast is assumed to be the vector of point predictions for that survey. The estimated densities allow the survey point predictions to be adjusted to satisfy the long-run moment restrictions. We make the smallest possible adjustments to the actual forecasts where 'smallest' is defined in relation to the estimated MVNs. Although we do not have to assume normality, given the limited information at our disposal it seems a reasonable working assumption.

As an illustration, consider the 1990Q3 survey. We take this as our first forecast origin for imposing restrictions - forecasts from prior surveys are used to estimate $\widehat{\Sigma}_{t+h}$, as follows. For the $h=4$ quarter ahead predictive density, we calculate the variance-covariance matrix using the

\footnotetext{
${ }^{12}$ The SPF does provide histograms for output growth (and for inflation) but not for consumption and investment. For output growth, the histograms refer to annual percentage growth in the survey year relative to the previous year, and in the next year relative to the current (survey) year. This gives rise to a sequence of fixed-event histogram forecasts of the annual growth rate for output. It was decided not to try and incorporate the density forecasts into the analysis, because of these timing issues and some doubts over the reliability of the within-year histogram forecasts: see Clements (2014).
} 
4-quarter ahead forecast errors associated with the forecasts from the 1981Q3 survey onwards. As we use real-time actuals available two quarters after the reference quarter, the most recent forecast we use is from the 1989Q1 survey. This is a forecast of 1990Q1, evaluated using the 1990Q3 vintage estimate of the actual value for 1990Q1. We estimate the covariance matrix using the usual autocorrelation-consistent estimator to account for the overlapping nature of the forecasts. We can calculate a MVN density for each $h$ (to allow restrictions to be imposed for each $h$ ), but expect the long-run restrictions to be relevant at the longer horizons, and this is borne out by our results.

We then construct the 1990Q4 survey forecast density in a similar way, but we now have additional past survey forecast errors (specifically, for $h=4$, the 1989Q2 survey forecast error of 1990Q2, based on the 1990Q4-vintage estimate of 1990Q2). We continue in this fashion up to the 2012Q2 survey. More recent surveys are available, but we stop with this survey so that the $h=4$ forecasts of this survey (of 2013Q2) can be evaluated using 2013Q4 actuals (the latest vintage available at the time of writing).

As well as assessing whether long-horizon growth rates can be improved by imposing longrun restrictions, section 3 indicates we ought also consider forecasts of the cointegrating combinations of the $(\log )$ levels. The SPF provides median forecasts of the levels, so it is a simple task to construct the MSE of the forecasts of linear combinations of these. To calculate the tilted forecasts, we use the tilted growth rate forecasts as follows. Let $X_{t+h \mid t}$ denote a log-level forecast from the SPF (where the forecast origin is $t$ ), then the exponentially-tilted log-level forecast is calculated as $X_{t+h \mid t}^{*}=X_{t+h-1 \mid t}+\mu_{t+h}^{*}$, that is, by adding the tilted (difference of the $\log$ ) growth rate forecast of $t+h$ to the survey level forecast of $t+h-1$.

Consider the forecasts of $\beta^{\prime}\left(C_{t+h} Y_{t+h}\right)^{\prime}$, where $C_{t+h}$ and $Y_{t+h}$ are the actual values of consumption and output, and $\beta^{\prime}=\left(1,-\beta_{2}\right)$, say. Then the tilted forecasts of the log levels of consumption and output at horizon $h, C_{t+h \mid t}^{*}$ and $Y_{t+h \mid t}^{*}$, are given by $C_{t+h \mid t}^{*}=C_{t+h-1 \mid t}+\mu_{c, t+h}^{*}$ and $Y_{t+h \mid t}^{*}=Y_{t+h-1 \mid t}+\mu_{y, t+h}^{*}$, where $\mu_{c, t+h}^{*}$ and $\mu_{y, t+h}^{*}$ are the tilted growth rate forecasts (satisfying $\left.\beta^{\prime}\left(\mu_{c, t+h}^{*}, \mu_{y, t+h}^{*}\right)^{\prime}=0\right)$. The $h$-step forecast error of the combination of the loglevels using the tilted forecasts is denoted by $e_{t+h, \beta}^{*}$, and is given by:

$$
e_{t+h, \beta}^{*}=\beta^{\prime}\left(C_{t+h}, Y_{t+h}\right)^{\prime}-\beta^{\prime}\left(C_{t+h \mid t}^{*}, Y_{t+h \mid t}^{*}\right)^{\prime}=\beta^{\prime}\left(C_{t+h}-C_{t+h-1 \mid t}, Y_{t+h}-Y_{t+h-1 \mid t}\right)^{\prime}
$$


If we were to evaluate the $\beta$-combination of the growth rates, then $e_{t+h, \beta \Delta}^{*}=\beta^{\prime}\left(\Delta C_{t+h}, \Delta Y_{t+h}\right)^{\prime}$, because $\beta^{\prime}\left(\Delta C_{t+h \mid t}^{*}, \Delta Y_{t+h \mid t}^{*}\right)^{\prime}=\beta^{\prime}\left(\mu_{c, t+h}^{*}, \mu_{y, t+h}^{*}\right)^{\prime}=0$. Hence when the moment restrictions imply long-run proportionality, i.e., $\beta^{\prime}=(1,-1)$, the forecast error in predicting the long-run combination of the growth rates is simply the difference between the consumption and output growth rates.

We can calculate the tilted log-level forecasts by cumulating a number of tilted growth rate forecasts. For example, $X_{t+h}^{*}=X_{t+h-2}+\mu_{t+h}^{*}+\mu_{t+h-1}^{*}$ is the log-level forecast of $t+h$ based on the reported forecast of $t+h-2$ and the two quarterly growth rates for the intervening periods (constructed to satisfy the moment restrictions).

In section 5.5 we investigate cumulating restricted growth rate forecasts in this way, as well as jointly estimating $\left(\mu_{t+h}^{*}, \mu_{t+h-1}^{*}\right)$ as opposed to estimating them independently. Our baseline results (section 5.2) neither cumulate growth rates nor jointly impose restrictions across forecast horizons.

Care is required when we evaluate the forecasts of the levels (or of the cointegrating combination of the levels) using real-time data. When the series are re-based the levels of the variables are shifted. This generally has little effect on the growth rates of the series and is usually ignored, but the same is not true when forecasts of the levels of the series are evaluated. ${ }^{13}$ Consider for example the forecasts of the levels of consumption (say) from the 1990Q3 survey. Following much of the literature, our preference is to use 'real-time' actuals: specifically those values available in the RTDSM 2-quarters after the reference quarter. This means that the longest-horizon forecast of 1991Q3 ought to be evaluated using the level of consumption in the 1992Q1 data vintage. However in 1992Q1 there was a re-basing of the data, and the level of consumption shifted up by some $20 \%$. Our solution is to create a series of real-time actual values purged of the effects of any re-basings. We explain how we do this with an example, again based on the 1990Q3 survey. The actual values against which we evaluate the levels forecasts from this survey are constructed as follows. The survey respondents have access to the 1990Q3 vintage value for 1990Q2, denoted $X_{90: 2}^{90: 3}$, so we assume their forecasts of future values are tuned to this. We calculate the $X_{90: 3}$ actual as $X_{90: 2}^{90: 3} \times\left(X_{90: 3}^{91: 1} / X_{90: 2}^{91: 1}\right)$, and the $X_{90: 4}$ actual

\footnotetext{
${ }^{13}$ See Clements and Galvão (2012) for a treatment of this problem in the context of estimating and forecasting with vintage-based vector autoregressions.
} 
as $X_{90: 2}^{90: 3} \times\left(X_{90: 4}^{91: 2} / X_{90: 2}^{91: 2}\right)$, and so on. That is, we calculate the level for $X_{90: 3}$ by multiplying the latest level (for 1990:2, from the 1990:3-data vintage) by the growth rate for 1990Q3 from the 1991Q1 vintage. For the next actual, we multiply $X_{90: 2}^{90: 3}$ by the two-quarter growth rate in the 1991:2 data vintage, and so on. We do this for all the 'actual values' for each survey quarter irrespective of whether re-basings take place or not. ${ }^{14}$ The differences between the purged-actuals and the actual-actuals are small in the absence of level shifts. ${ }^{15}$

\section{Results}

The two key questions are i) whether the long-horizon expectations of the survey forecasters taken together satisfy theory-based restrictions; and ii) if not, whether the imposition of such restrictions on the survey forecasts improves their accuracy.

\subsection{Do the reported median forecasts satisfy the two-sector model moment restrictions?}

Table 3 reports the mean changes in the reported and tilted forecasts for the $h=4$ horizon, when the tilting is based on imposing the two-sector model restriction. (The forecasts are multiplied by 100 for ease of interpretability). Imposing the consumption-output long-run restriction has virtually no effect on the forecasts of consumption growth, but alters the forecasts of quarterly output growth by 0.14 percentage points for the forecasts made in response to the surveys 1990:Q3 to 2012:Q2 inclusive. Imposing the investment-output restriction has a more marked effect on the reported forecasts, and in this case the brunt of the adjustment is borne by investment, because of the greater uncertainty surrounding the investment forecasts. The average (absolute) change in investment is 0.41 percentage points, and that for output is 0.10 percentage points. The table also indicates a greater average change in the combination of investment and output from imposing the restrictions (compared to the change in the consumption-output combination).

\footnotetext{
${ }^{14}$ The RTDSM do not record values for $Y_{95: 4}^{96: 1}$, and we calculate values for the $1996 \mathrm{Q} 1$ survey by applying growth rates as above to the survey median forecast of the previous quarter.

${ }^{15} \mathrm{We}$ adjust the non-logged levels of the actual data (as described in the text). We then calculate the differences of the logs of the adjusted data, and the combinations of the log levels, to use as actual values for forecast evaluation.
} 
Table 3 establishes that imposing both long-run restrictions alters the forecasts of the growth rates and the linear combinations by relatively large amounts in the case of investment, and to a lesser degree for the consumption-output restriction. The next step is to assess the impact on forecast accuracy.

\subsection{Forecast accuracy and the two-sector model moment restrictions}

Table 4 presents the MSEs for the SPF forecasts of the growth rates for the current (survey quarter) and next 4 quarters, for all forecast origins, and also excluding the recent turbulent period. The current-quarter MSEs for consumption and output growth are similar, while investment growth is more difficult to forecast at longer horizons. The MSEs for investment are an order of magnitude larger, reflecting the more volatile movements in this variable, especially during the Crisis period.

Table 5 shows the results of imposing long-run restrictions in terms of the accuracy of forecasting growth rates and linear combinations of the levels. Panel A records the results of treating consumption and output as a bivariate system, and investment and output as a separate bivariate system. Hence in terms of equation (2), $\Sigma_{t+h}$ is the 2 by 2 covariance matrix calculated from earlier survey forecast errors, and $\beta^{\prime}=\left(1,-\beta_{2}\right)$. There are two entries for output, Output ${ }_{c}$ and Output ${ }_{i}$, denoting whether the tilted survey output growth forecasts are obtained from the consumption-output $\left(\beta_{2}=0.95\right)$, or the investment-output $\left(\beta_{2}=1.35\right)$ system. In panel B we report the results for the three-variable system, whence $\Sigma_{t+h}$ is a 3 by 3 covariance matrix and:

$$
\beta^{\prime}=\left[\begin{array}{lll}
1 & 0 & -0.95 \\
0 & 1 & -1.35
\end{array}\right]
$$

(when the variables are ordered as consumption, investment and output). In both panels A and $\mathrm{B}$ the MSEs of the tilted forecasts are presented as ratios of the MSEs of the survey forecasts. We report results for $h=3$ and $h=4$, as the restrictions are only relevant for the longer-horizon forecasts. We again show the effect of excluding the more recent forecasts. Considering the whole period, we find that imposing the consumption-output long-run restriction has no effect on the accuracy of the consumption growth forecasts (unsurprisingly, given that these barely change: see table 3) and that the changes to the output growth forecasts result in modest 
improvements in accuracy of $2 \%$. These latter gains vanish if we exclude the more turbulent years. Imposing the long-run investment-output restriction worsens the forecasts of investment and output, by around $5 \%$ and $3 \%$, respectively (all forecasts, $h=4$ ). Simultaneously restricting all three growth rates (with $\beta$ defined as in (3)) does not improve on the reported forecasts. That long-run restrictions might be less likely to be effective when forecasts are evaluated in growth rates is consistent with the analysis referred to in section 3.

Panel $\mathrm{C}$ of table 5 presents the results for forecasting the linear combinations of (the $\log$ levels of) the variables. ${ }^{16}$ The tilted forecasts of the (log) consumption/output combination are $6 \%$ more accurate than the same combination of the reported forecasts at $h=4$, irrespective of whether the model recent years are included, but the investment-output restriction worsens the accuracy with which the investment-output combination is forecast. ${ }^{17}$

Many of the differences in table 5 between the accuracy of the reported forecasts and the tilted forecasts are small. We consider two related questions: $i$ ) whether the differences in forecast accuracy between the reported and tilted forecasts are statistically significant, and $i i$ ) whether one set of forecasts contains information not contained in the other. For example, we might be unable to reject the null that the two sets of forecasts are equally accurate, but nevertheless find that one forecast fails to encompass another, i.e., that one forecast contains useful information (in terms of more accurately predicting the target) not contained in the other. As a test for equal forecast accuracy, we use an adjusted version of the DM test of Diebold and Mariano (1995), and we follow Harvey, Leybourne and Newbold (1998) and West (2001) in considering tests of forecast encompassing which are also based on the Diebold and Mariano (1995) (DM)-type approach. (Clark and McCracken (2011) and Clements and Harvey (2009) provide recent reviews of testing for predictive ability and forecast encompassing).

The test of forecast encompassing is due to Fair and Shiller (1990) (see also Chong and

\footnotetext{
${ }^{16}$ Similar results were obtained if we evaluated accuracy in terms of forecasts of the linear combinations of the growth rates rather than the levels.

${ }^{17}$ Note that the results for forecasting linear combinations of the levels are the same for the bivariate and trivariate systems by construction provided the same restrictions are imposed. Using the notation in section 4 ,

$$
\beta^{\prime}\left(C_{t+h \mid t}^{*}, Y_{t+h \mid t}^{*}\right)^{\prime}=\beta^{\prime}\left(C_{t+h-1 \mid t}, Y_{t+h-1 \mid t}\right)^{\prime}+\beta^{\prime}\left(\mu_{c, t+h}^{*}, \mu_{y, t+h}^{*}\right)^{\prime}
$$

and the last term will vanish whether $\left(\mu_{c, t+h}^{*}, \mu_{y, t+h}^{*}\right)$ is estimated using a two or three variable system.
} 
Hendry (1986)), and is whether $\beta_{2}=0$ in:

$$
y_{t}=\alpha+\beta_{1} f_{1 t}+\beta_{2} f_{2 t}+\varepsilon_{t}
$$

where $f_{1 t}$ and $f_{2 t}$ are the two sets of forecasts (here the reported and tilted forecasts), and the alternative is usually one-sided, $\beta_{2}>0$. That is, we test whether excluding $f_{2 t}$ from the combination of forecasts does not result in a statistically significant increase in expected squared-error loss (say), against the alternative that a combination of the two forecasts with a positive weight on $f_{2 t}$ results in a more accurate forecast. Extending Harvey et al. (1998), Clements and Harvey (2010) note that the population parameter $\beta_{2}$ in (4) is identical to $\beta_{2}$ in:

$$
\eta_{1 t}=\beta_{2} \eta_{2 t}+\nu_{t}
$$

where $\eta_{1 t}$ and $\eta_{2 t}$ are the errors from the regression of $y_{t}$ and $f_{2 t}$, respectively, on a constant and $f_{1 t}$. Hence the null of $\beta_{2}=0$ therefore holds when $E\left(\eta_{1 t} \eta_{2 t}\right)=0$. They suggest using a DM approach based on $d_{t}=\hat{\eta}_{1 t} \hat{\eta}_{2 t}$, where $\hat{\eta}_{1 t}$ and $\hat{\eta}_{2 t}$ denote the corresponding regression residuals, and where:

$$
\mathrm{DM}=\frac{n \bar{d}}{\sqrt{\sum_{\tau=-(h-1)}^{h-1} \sum_{t=|\tau|+1}^{n}\left(d_{t}-\bar{d}\right)\left(d_{t-|\tau|}-\bar{d}\right)}}
$$

and the modified DM test with improved small-sample performance is:

$$
\mathrm{MDM}=n^{-1 / 2}\left[n+1-2 h+n^{-1} h(h-1)\right]^{1 / 2} D M
$$

with $\bar{d}=n^{-1} \sum_{t=1}^{n} d_{t}$. The MDM test is compared to a Student $t$ distribution with $n-1$ degrees of freedom.

The test for equal accuracy uses MDM but with $d_{t}=\left(y_{t}-f_{1 t}\right)^{2}-\left(y_{t}-f_{2 t}\right)^{2}$, where the test is now two-sided.

These tests are applied to the forecasts reported in panels $\mathrm{A}$ and $\mathrm{C}$ of table 5 . We considered only the $h=4$ forecasts, and set $h=4$ in (5) to account for the overlapping nature of the 
forecasts, ${ }^{18}$ and calculated statistics for the whole period (1990:Q3 to 2012:Q2).

For the comparisons of growth rates in panel A, there were no significant differences in forecast accuracy at conventional levels, or rejections of the null of forecast encompassing, in either direction. The former finding is unsurprising give the small differences in MSE in panel A. The latter indicates that in addition neither set of forecasts contains useful information not available in the other. These outcomes are not reported.

However, the gain to the tilted forecasts of the consumption/output ratio was statistically significant at the $10 \%$ level in a two-sided test (MDM test statistic of 1.68 , where ' $f_{1}$ ' and ' $f_{2}$ ' refer to the reported and tilted forecasts, respectively, with two sided critical values of \pm 1.66 at the $10 \%$ level). The forecast encompassing test of the reported $\left(f_{1}\right)$ encompassing the tilted $\left(f_{2}\right)$ was rejected at the $15 \%$ level, but there was no evidence against the null when the test was run in the reverse direction. For the investment-output ratio, the tilted forecasts were statistically less accurate (MDM statistic of -1.86). Moreover, there was no evidence against the null that the reported encompassed the tilted (and the hypothesis that the tilted encompassed the reported was rejected at the $5 \%$ level).

\subsection{Stability of forecast performance over time}

Our forecast period (the surveys from 1990Q3 to 2012Q2) covers two decades, and includes the 2001Q1-Q4 and the 2007Q4-2009Q2 recessions. We have reported results that exclude the latest recession, but in this section we undertake a more indepth investigation of whether the relative usefulness of imposing the long-run restrictions changes over time. We calculate rolling estimates of the ratios of the MSEs. For each point in time, beginning with 1995Q2, we calculate the MSE of the errors corresponding to forecasts made in that survey and in the 19 previous surveys. So the 2012Q2 observation is the ratio of MSEs calculated using the surveys from 2007Q3 to 2012Q2, inclusive (of the year ahead forecasts of 2008Q3 to 2013Q2).

Figure 6 plots the rolling estimates of the MSE ratios of the tilted and reported growth rate forecasts for the $h=4$ horizon. The first panel refers to consumption and output, and the second to investment and output, and the restrictions are $(1:-0.95)$ and $(1:-1.35)$, respectively.

\footnotetext{
${ }^{18}$ Although we term the forecasts $h=4$, they are $h=5$ for determining the degree of overlap, and the appropriate order of autocorrelation-correction. Hence the appropriate order is one less, at 4.
} 
From the first panel it is apparent that the accuracy of the tilted and reported consumption growth forecasts is virtually the same throughout the period, whereas the tilted output growth forecasts are superior except for a period in the run-up to the recession. In the second panel for the investment-output system there is also a tendency for the tilted investment and output forecasts to worsen in the lead up to the crisis, and thereafter they remain less accurate than the reported forecasts.

Figure 7 plots the MSE estimates for the forecasts of the combinations of the log-levels of the variables. The tilted forecasts of the consumption-output combination are more accurate than the reported forecasts for the rolling 5-year windows throughout the last decade. Imposing restrictions improves the accuracy of the investment-output combination during the period 2001-5, but has a negative impact thereafter.

\subsection{Estimating the long-run relationships}

We investigate whether our results are sensitive to allowing the long-run restrictions to change over time. At each forecast origin we estimate the cointegrating relations using the vectorautoregression maximum likelihood estimator of Johansen (1988). This allows for the possibility that the global values assumed in section 5.2 may not hold over the whole forecast period. Because we wish to estimate two distinct cointegrating relationships, the Johansen approach is ideal. We allow two lags in differences (i.e., a third-order VAR in the levels of the variables), and include an unrestricted constant term (see e.g. Johansen (1995)). We estimate bivariate systems for consumption and output, and for investment and output, separately, and a joint system for the three variables. We assume that there is one cointegrating vector for the two bivariate systems, and two for the last model, as the analysis in this paper is predicated on the existence of long-run relationships. For each survey, we estimate the cointegrated VAR using a window of 25 years of data from the vintage of data available at that point in time. Figure 8 records the estimates of $\beta_{c}$ and $\beta_{i}$ in the cointegrating vectors normalized as:

$$
\hat{\beta}^{\prime}=\left[\begin{array}{ccc}
1 & 0 & -\hat{\beta}_{c} \\
0 & 1 & -\hat{\beta}_{i}
\end{array}\right]
$$


in the trivariate system, such that the linear combinations are given by $c-\hat{\beta}_{c} y$ and $i-\hat{\beta}_{i} y$. The results reported thus far set $\beta_{c}=0.95$ and $\beta_{i}=1.35$ across the whole period 1990Q3 to 2012:Q2. From the top panel of figure 8 it is apparent that $\beta_{c}$ is close to unity throughout, but that $\beta_{i}$ trends upward from the mid 1990's onwards. The bottom panel reports the estimates of the trace statistic of the null of no more than one cointegrating vector on each rolling window. The evidence for two cointegrating vectors over the period 1995-2010 is far from persuasive: the formal tests indicate a single cointegrating relationship between the three variables over the last 10-15 years. We interpret the results of the Johansen procedure as casting doubt on the existence of an equilibrium relationship between investment and output.

Nevertheless, to check the robustness of the results based on imposing $(1:-0.95)$ and $(1:-1.35)$, we tilted the forecasts of the growth rates using the estimates of the long-run relations obtained at each survey origin. We found that the tilted forecasts based on the estimated long-run relationships were no more accurate than assuming constant growth rates over the whole period, and are not reported to save space.

\subsection{Further robustness checks}

We experimented with jointly tilting the $h=3$ and $h=4$ forecasts (as discussed at the end of section 2) in bivariate systems using the two-sector model restrictions. Doing so had only small effects on the growth rate forecasts and little appreciable effect on their accuracy, and the results are not reported.

In principle, one might wish to impose cumulative restrictions, for example, that both the $h$-step and $h-1$-step ahead growth rate forecasts satisfy the long-run restrictions (and not just the $h$-step forecasts). The last $s$ forecasts could be restricted by calculating the tilted $h$-step ahead $(\log )$ level forecasts as:

$$
Y_{t+h \mid t}^{*}=\sum_{i=0}^{s-1} \mu_{t+h-i}^{*}+Y_{t+h-2-s \mid t},
$$

and the $\mu^{*}$ could be estimated separately for each horizon, or jointly. We did not pursue this approach here because of the nature of the forecast data, namely, only the longest horizon forecasts can be regarded as long-horizon forecasts. 


\section{Conclusions}

Median survey forecasts aggregate vast amounts of information and reflect judgement about the effects of events currently in train and those which are expected to impact on the economy in the future. Hence it is perhaps unsurprising that survey expectations can lead to marked improvements in models' short-term predictions, as found by e.g., Clements (2015). In this paper we consider whether long-run restrictions relating to steady-state growth rates can usefully be applied to long-horizon survey forecasts.

Our interest is in better understanding how macroeconomic forecasters forecast, and in particular, whether their forecasts are informed by the belief that key economic variables satisfy steady-state growth paths. Imposing the consumption-output restriction in an optimal fashion affects the long-horizon forecasts of consumption and output, with the vast majority of the adjustment falling on output. We find the reverse is the case for the investment-output restriction: the brunt of the adjustment is borne by investment (with a mean absolute change of almost half a percentage point each period in the forecast growth rate). The answer to the question of whether these restrictions improve forecast accuracy is more equivocal. Imposing the consumption-output restrictions generates small improvements in MSE of 2 percent, and the long-run steady state combination of consumption and output is forecast more accurately, but there is no benefit to imposing the investment-output restriction. That there may be more discriminatory power from evaluating rival forecasts in terms of the cointegrating combinations of the levels was a point first made by Clements and Hendry (1995).

As well as suggesting a clear dichotomy between imposing long-run restrictions based on the relationship between consumption and output and that between investment and output, it is also clear that the relative value of tilting varies over time, and we document this in the paper. The value of imposing the investment-output restrictions may be tempered by the ratio of the steady-state growth rates of investment and output drifting over time, as suggested by the changing estimates of the cointegrating combination.

There are a number of avenues that might be worth pursuing. In terms of imposing restrictions on long-horizon survey forecasts, a possible drawback of the US SPF remains that a one-year ahead forecast might not be an adequate proxy of a long-horizon forecast, even though the evidence presented in section 4 is broadly supportive. If suitable surveys were available, it 
would be interesting to carry out a similar analysis. Secondly, we have considered the median forecasts, whereas in principle the long-run restrictions could be applied to each individual's forecasts. This would be complicated by the average individual providing only a relatively small number of forecasts given the requirement of calculating the covariance matrices of forecast errors, but a work-around may be possible. Finally, restrictions other than long-run restrictions might be imposed. For example, Devereux, Smith and Yetman (2012) and Smith and Yetman (2013) investigate whether implications of dynamic consumption theory hold in survey data, but do not consider whether the imposition of such restrictions might improve the accuracy of the survey forecasts. 


\section{References}

Altavilla, C., Giacomini, R., and Ragusa, G. (2014). Anchoring the yield curve using survey expectations. Discussion paper, European Central Bank, Working Paper Series 1632.

Batchelor, R., and Dua, P. (1991). Blue Chip rationality tests. Journal of Money, Credit and Banking, 23, 692-705.

Branch, W. (2004). The theory of rationally heterogeneous expectations: Evidence from survey data on inflation expectations. Economic Journal, 114, 592-621.

Chong, Y. Y., and Hendry, D. F. (1986). Econometric evaluation of linear macro-economic models. Review of Economic Studies, 53, 671-690. Reprinted in Granger, C. W. J. (ed.) (1990), Modelling Economic Series. Oxford: Clarendon Press.

Clark, T. E., and McCracken, M. W. (2011). Testing for unconditional predictive ability. In Clements, M. P., and Hendry, D. F. (eds.), The Oxford Handbook of Economic, pp. 415440: Oxford University Press.

Clements, M. P. (2014). Forecast Uncertainty - Ex Ante and Ex Post: US Inflation and Output Growth. Journal of Business \& Economic Statistics, 32(2), 206-216. DOI: 10.1080/07350015.2013.859618.

Clements, M. P. (2015). Are professional macroeconomic forecasters able to do better than forecasting trends?. Journal of Money, Credit and Banking, 47,2-3, 349-381. DOI: 10.1111/jmcb.12179.

Clements, M. P., and Galvão, A. B. (2012). Improving real-time estimates of output gaps and inflation trends with multiple-vintage VAR models. Journal of Business $\&$ Economic Statistics, 30(4), 554-562. DOI: 10.1080/07350015.2012/707588.

Clements, M. P., and Harvey, D. I. (2009). Forecasting combination and encompassing. In Mills, T. C., and Patterson, K. (eds.), Palgrave Handbook of Econometrics, Volume 2: Applied Econometrics, pp. 169-198: Palgrave MacMillan.

Clements, M. P., and Harvey, D. I. (2010). Forecast encompassing tests and probability forecasts. Journal of Applied Econometrics, 25, 1028-1062.

Clements, M. P., and Hendry, D. F. (1995). Forecasting in cointegrated systems. Journal of 
Applied Econometrics, 10, 127-146.

Croushore, D. (1993). Introducing: The Survey of Professional Forecasters. Federal Reserve Bank of Philadelphia Business Review, "November", 3-15.

Croushore, D., and Stark, T. (2001). A real-time data set for macroeconomists. Journal of Econometrics, 105(1), 111-130.

Davidson, J. E. H., Hendry, D. F., Srba, F., and Yeo, J. S. (1978). Econometric modelling of the aggregate time-series relationship between consumers' expenditure and income in the United Kingdom. Economic Journal, 88, 661-692.

Del Negro, M., and Schorfheide, F. (2013). DSGE model-based forecasting. In Elliott, G., and Timmermann, A. (eds.), Handbook of Economic Forecasting, Volume 2., pp. 57-140: Amsterdam, Horth-Holland.

Devereux, M. B., Smith, G. W., and Yetman, J. (2012). Consumption and real exchange rates in professional forecasts. Journal of International Economics, 86(1), 33-42.

Diebold, F. X., and Mariano, R. S. (1995). Comparing predictive accuracy. Journal of Business and Economic Statistics, 13, 253-263. Reprinted in Mills, T. C. (ed.) (1999), Economic Forecasting. The International Library of Critical Writings in Economics. Cheltenham: Edward Elgar.

Engle, R. F., and Granger, C. W. J. (1987). Cointegration and error correction: Representation, estimation and testing. Econometrica, 55, 251-276.

Evans, G. W., and Honkapohja, S. (2001). Learning and Expectations in Macroeconomics. Princeton: Princeton University Press.

Evans, G. W., and Ramey, G. (1992). Expectation calculation and macroeconomic dynamics. American Economic Review, 82, 207-224.

Fair, R. C., and Shiller, R. J. (1990). Comparing information in forecasts from econometric models. American Economic Review, 80, 39-50.

Giacomini, R., and Ragusa, G. (2014). Theory-coherent forecasting. Journal of Econometrics, 182(1), 145-155.

Giacomini, R. (2011). Testing conditional predictive ability. In Clements, M. P., and Hendry, D. F. (eds.), The Oxford Handbook of Economic, pp. 441-455: Oxford University Press. 
Harvey, D. I., Leybourne, S., and Newbold, P. (1998). Tests for forecast encompassing. Journal of Business and Economic Statistics, 16, 254-259. Reprinted in T.C. Mills (ed.), Economic Forecasting. Edward Elgar, 1999.

Hommes, C. (2006). Heterogeneous agent models (HAMs) in economics and finance. In Judd, K. L., and Tesfatsion, L. (eds.), Handbook of Computational Economics, Volume 2, Agentbased Computational Economics. Amsterdam: North Holland.

Johansen, S. (1988). Statistical analysis of cointegration vectors. Journal of Economic Dynamics, 12, 231-254.

Johansen, S. (1992). A representation of vector autoregressive processes integrated of order 2. Econometric Theory, 8, 188-202.

Johansen, S. (1995). Likelihood-Based Inference in Cointegrated Vector Autoregressive Models. Oxford: Oxford University Press.

Keane, M. P., and Runkle, D. E. (1990). Testing the rationality of price forecasts: new evidence from panel data. American Economic Review, 80(4), 714-735.

King, R. G., Plosser, C. I., Stock, J. H., and Watson, M. W. (1991). Stochastic trends and economic fluctuations. American Economic Review, 81, 819-840.

Kitamura, Y., and Stutzer, M. (1997). An information theoretic alternative to generalized method of moments estimation. Econometrica, 65(4), 861-874.

Kosobud, R., and Klein, L. (1961). Some econometrics of growth: Great ratios of economics. Quarterly Journal of Economics, 25, 173-198.

Robertson, J. C., Tallman, E. W., and Whiteman, C. H. (2005). Forecasting using relative entropy. Journal of Money, Credit and Banking, 37(3), 383-401.

Sargan, J. D. (1964). Wages and prices in the United Kingdom: A study in econometric methodology (with discussion). In Hart, P. E., Mills, G., and Whitaker, J. K. (eds.), Econometric Analysis for National Economic Planning, Vol. 16 of Colston Papers, pp. 25-63. London: Butterworth Co.

Sargent, T. J. (1993). Bounded Rationality in Macroeconomics. Oxford: Oxford University Press.

Smets, F., Warne, A., and Wouters, R. (2014). Professional forecasters and real-time forecasting 
with a DSGE model. International Journal of Forecasting, 30, 981-995.

Smith, G. W., and Yetman, J. (2013). Estimating dynamic euler equations with multivariate professional forecasts. Economic Inquiry, 51(1), 445-458.

Stutzer, M. (1996). A simple nonparametric approach to derivative security valuation. The Journal of Finance, 51(5), 1633-1652.

West, K. D. (2001). Tests for forecast encompassing when forecasts depend on estimated regression parameters. Journal of Business and Economic Statistics, 19, 29-33.

Whelan, K. (2003). A Two-Sector Approach to Modeling U.S. NIPA Data. Journal of Money, Credit and Banking, 35(4), 627-56.

Wright, J. H. (2013). Evaluating Real-Time VAR forecasts with an informative democratic prior. Journal of Applied Econometrics, 28, 762-776. DOI: 10.1002/jae.2268.

Zarnowitz, V. (1969). The new ASA-NBER Survey of Forecasts by Economic Statisticians. The American Statistician, 23, No. 1, 12-16.

Zarnowitz, V., and Braun, P. (1993). Twenty-two years of the NBER-ASA quarterly economic outlook surveys: aspects and comparisons of forecasting performance. In Stock, J., and Watson, M. (eds.), Business Cycles, Indicators, and Forecasting, pp. 11-84: Chicago: University of Chicago Press and NBER. 


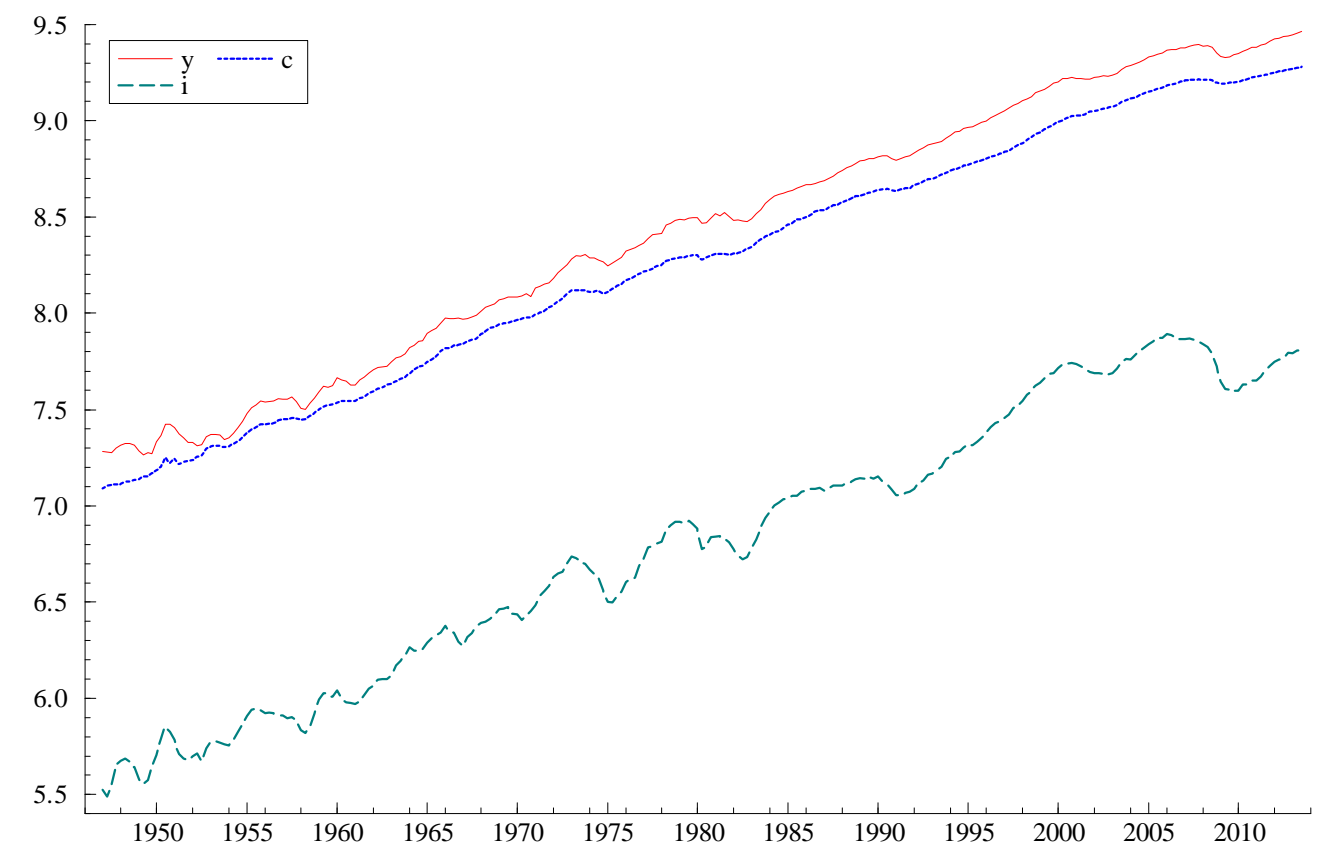

Figure 1: Natural logarithms of consumption $c$, investment $i$ and 'private' GDP $y$ over the period 1947Q1 to 2013Q3, from the 2013Q4 data vintage. 

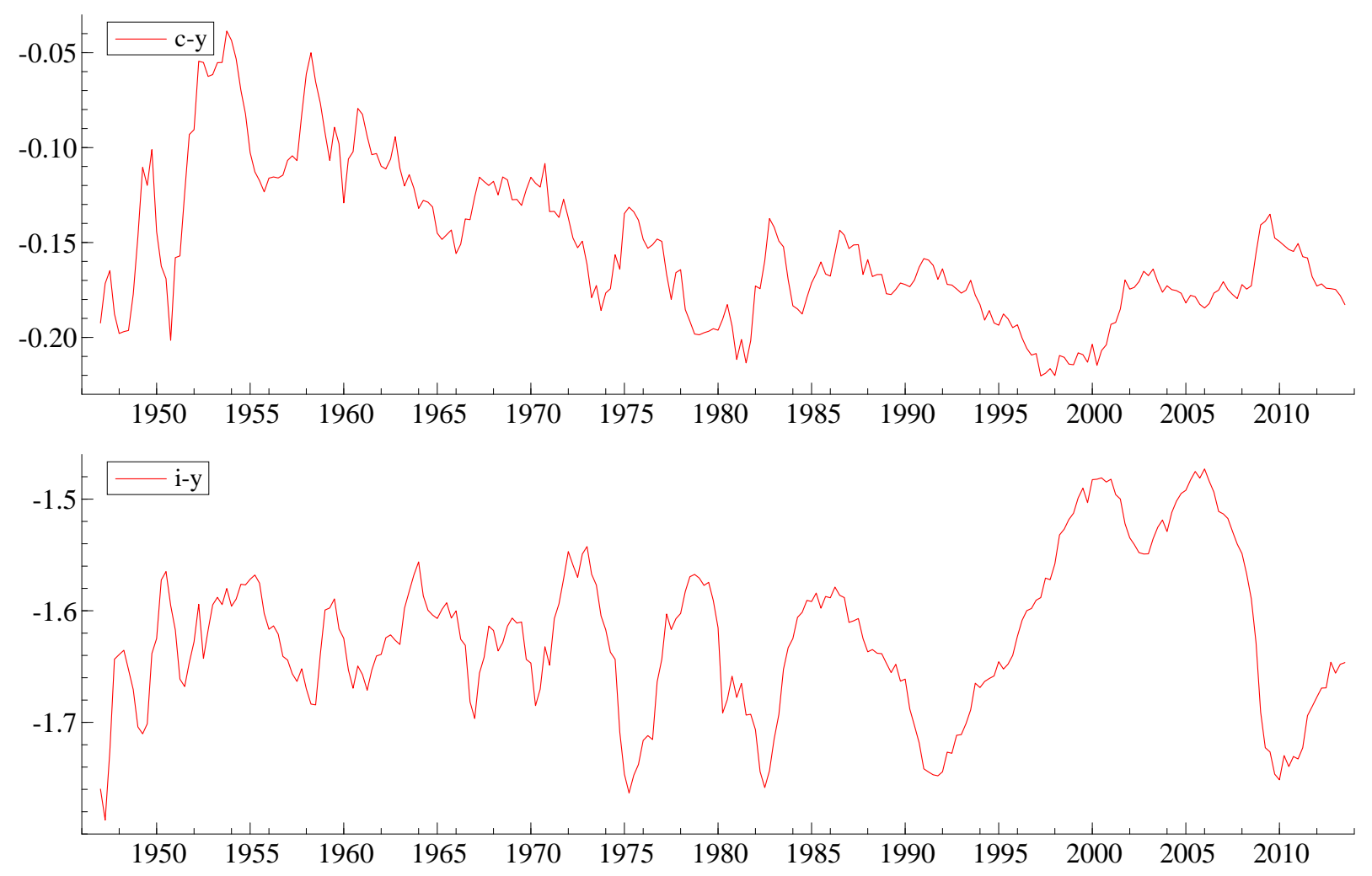

Figure 2: The logs of the ratio of consumption to output (c-y, top panel) and of the ratio of investment to output ( $i-y$, bottom panel), 1947Q1 to 2013Q3, from the 2013Q4 data vintage. 


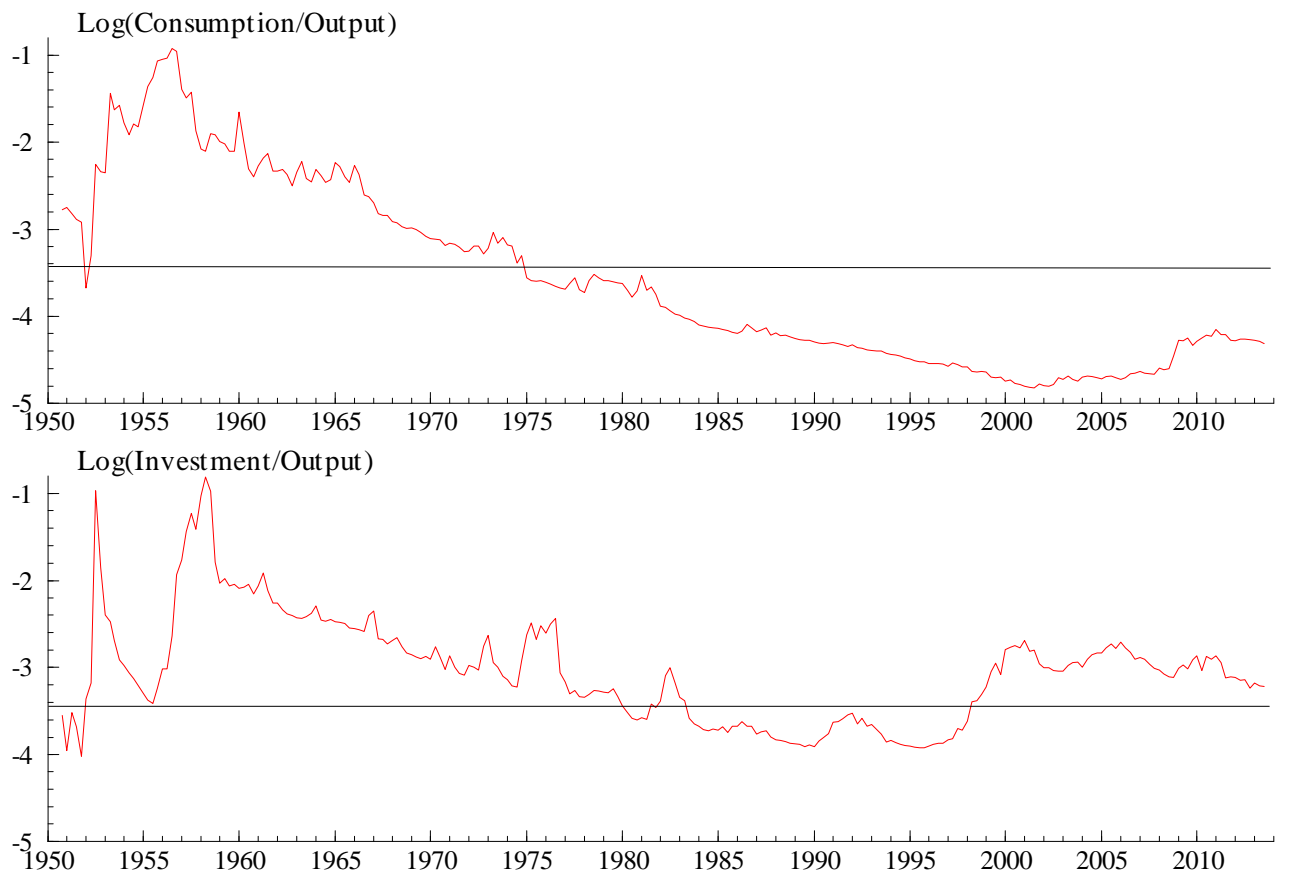

Figure 3: Recursive estimates of ADF $t$-statistics of a unit root in each of the two ratios (constant, trend and four lagged differences). Asymptotic 5\% critical value is -3.43 (marked on graph). 

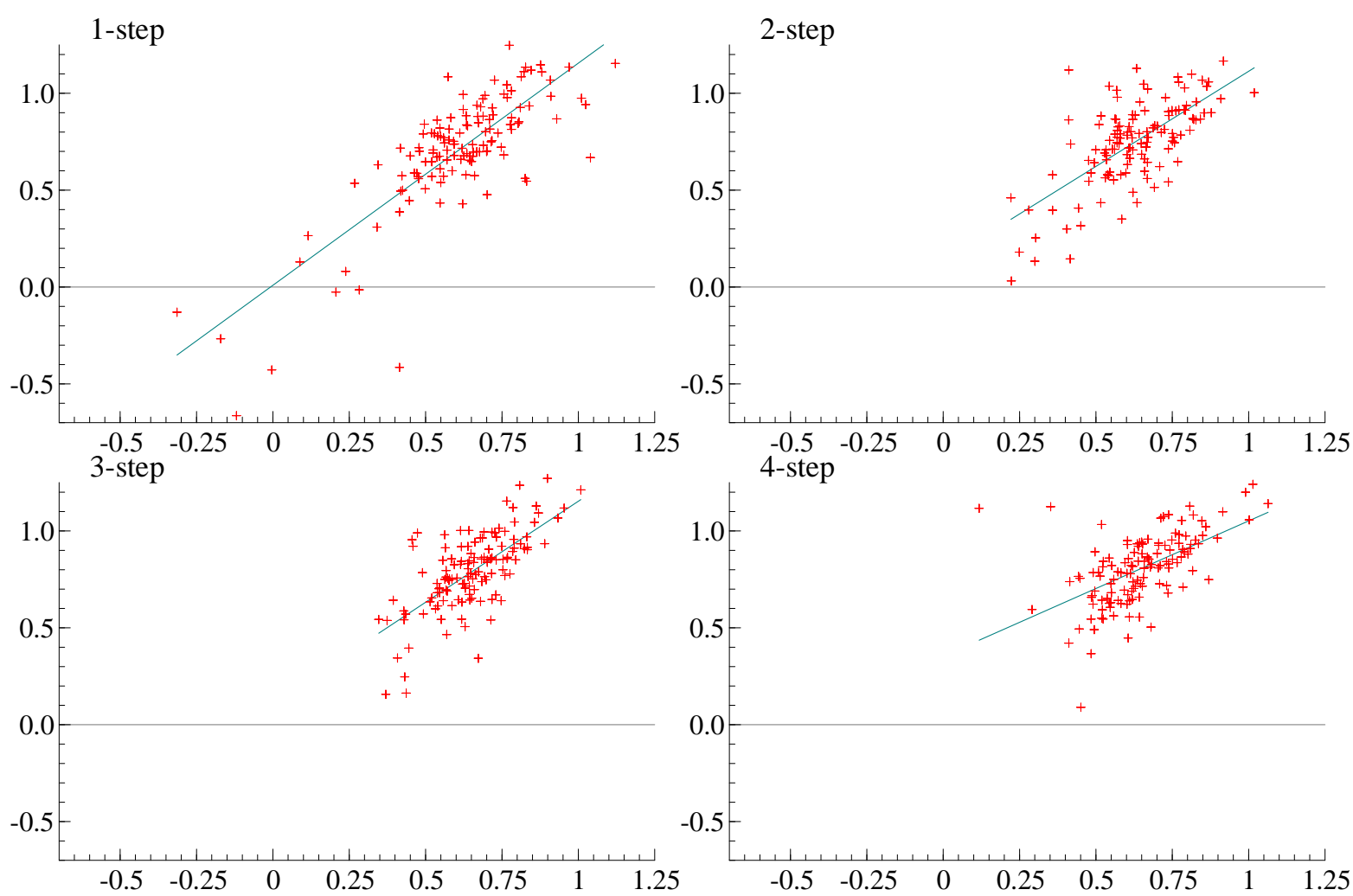

Figure 4: Scatter plots of 1 to 4 quarter ahead forecasts of quarterly output growth ( $y$-axis) and consumption growth ( $x$-axis). (The forecasts are of quarterly percentage growth rates, for the period 1981Q3 to 2012Q2). 

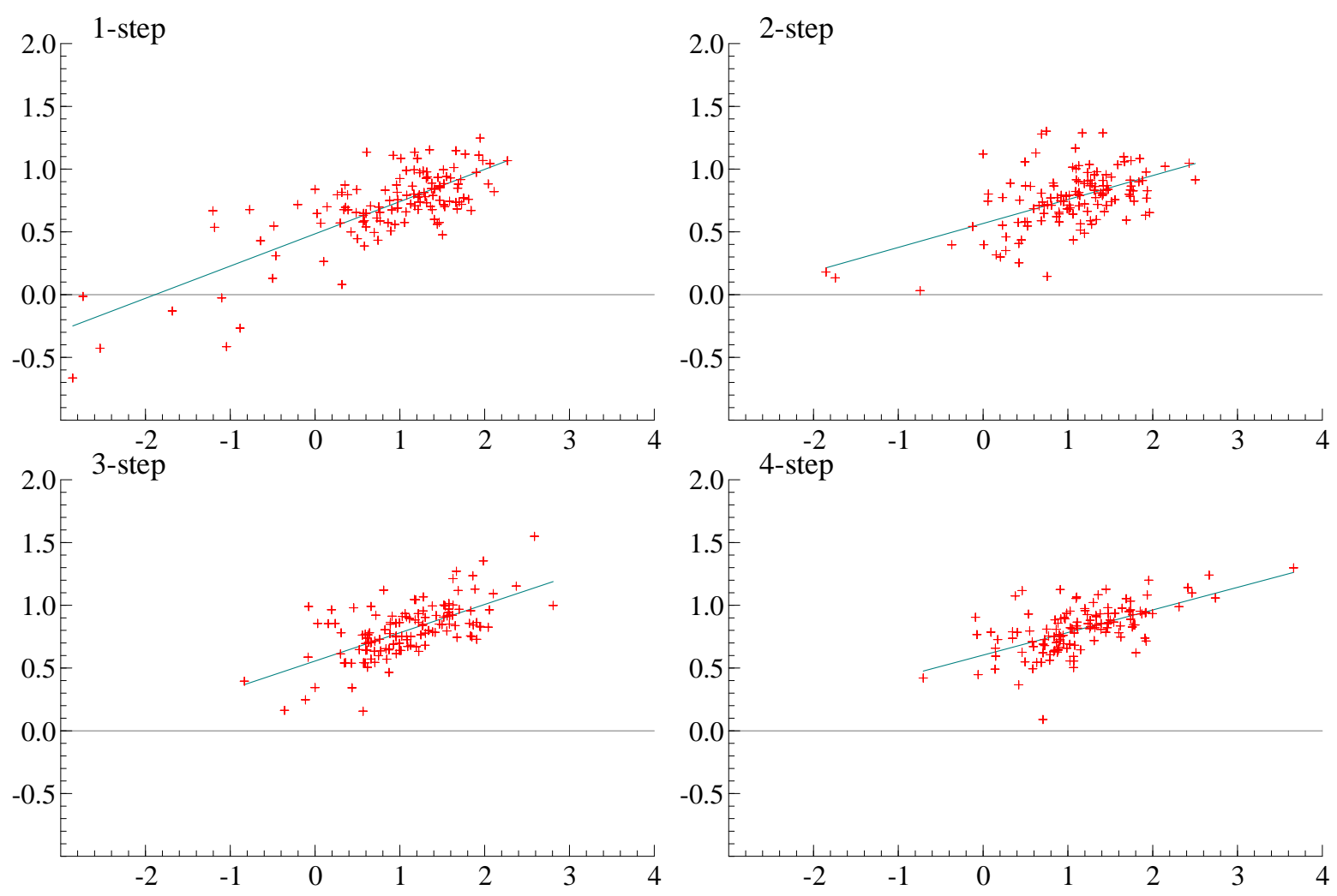

Figure 5: Scatter plots of 1 to 4 quarter ahead forecasts of quarterly output growth ( $y$-axis) and investment growth (x-axis). (The forecasts are of quarterly percentage growth rates, for the period 1981Q3 to 2012Q2). 

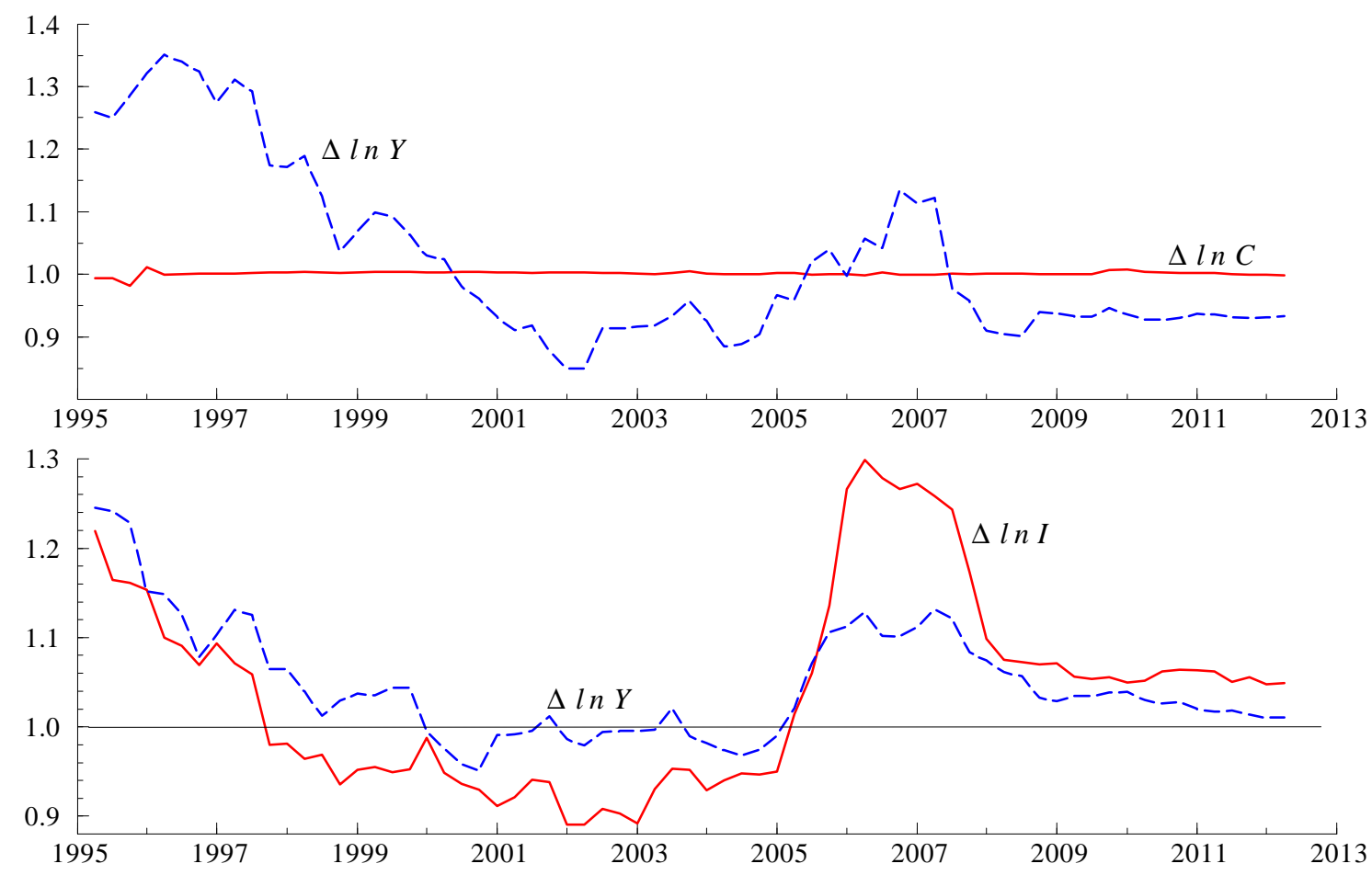

Figure 6: Rolling window MSEs of the tilted forecasts of the growth rates (differences of logs) to the reported forecasts, for the year-ahead $(h=4)$ forecasts. 


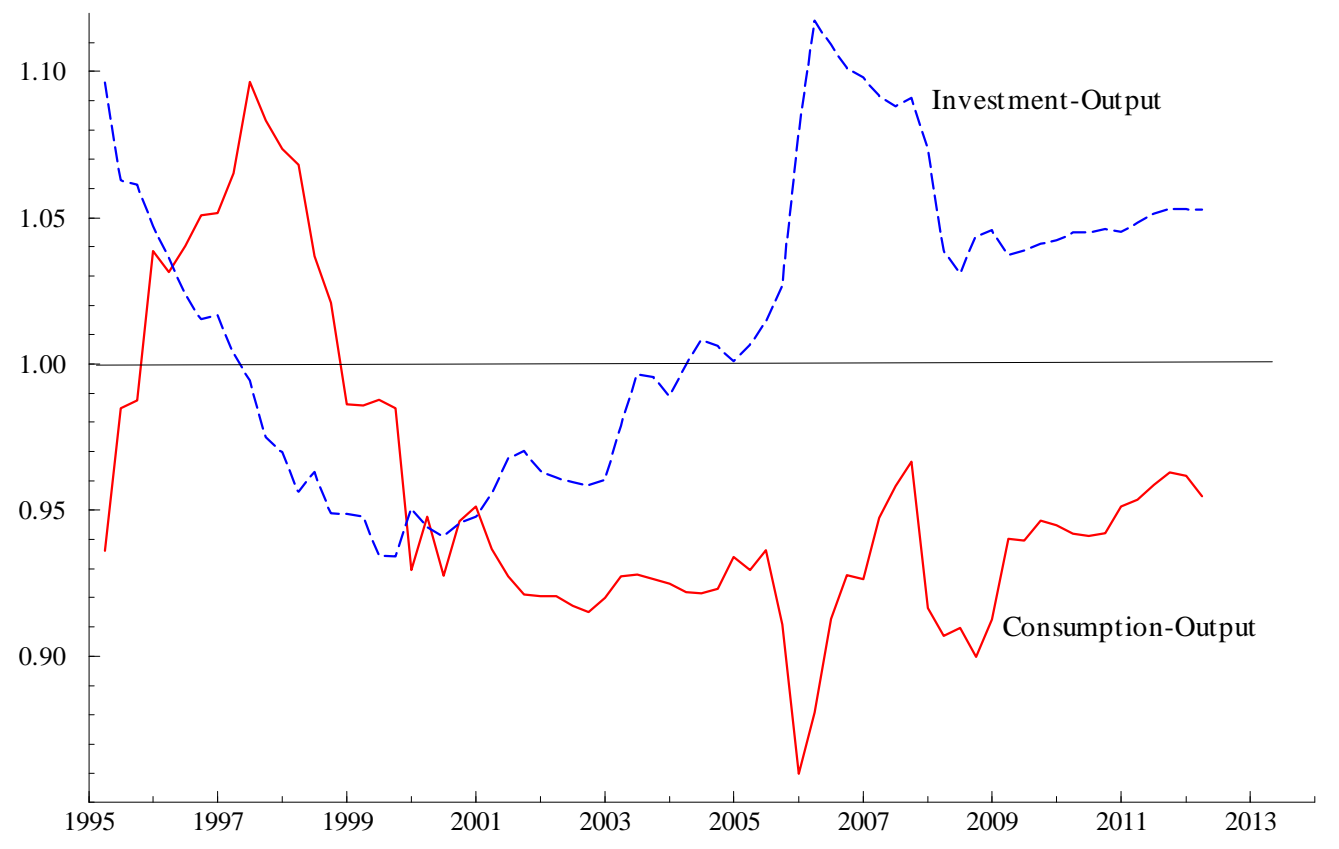

Figure 7: Rolling window MSEs of the tilted forecasts of the cointegrating combinations to reported forecasts, for the year-ahead $(h=4)$ forecasts. 

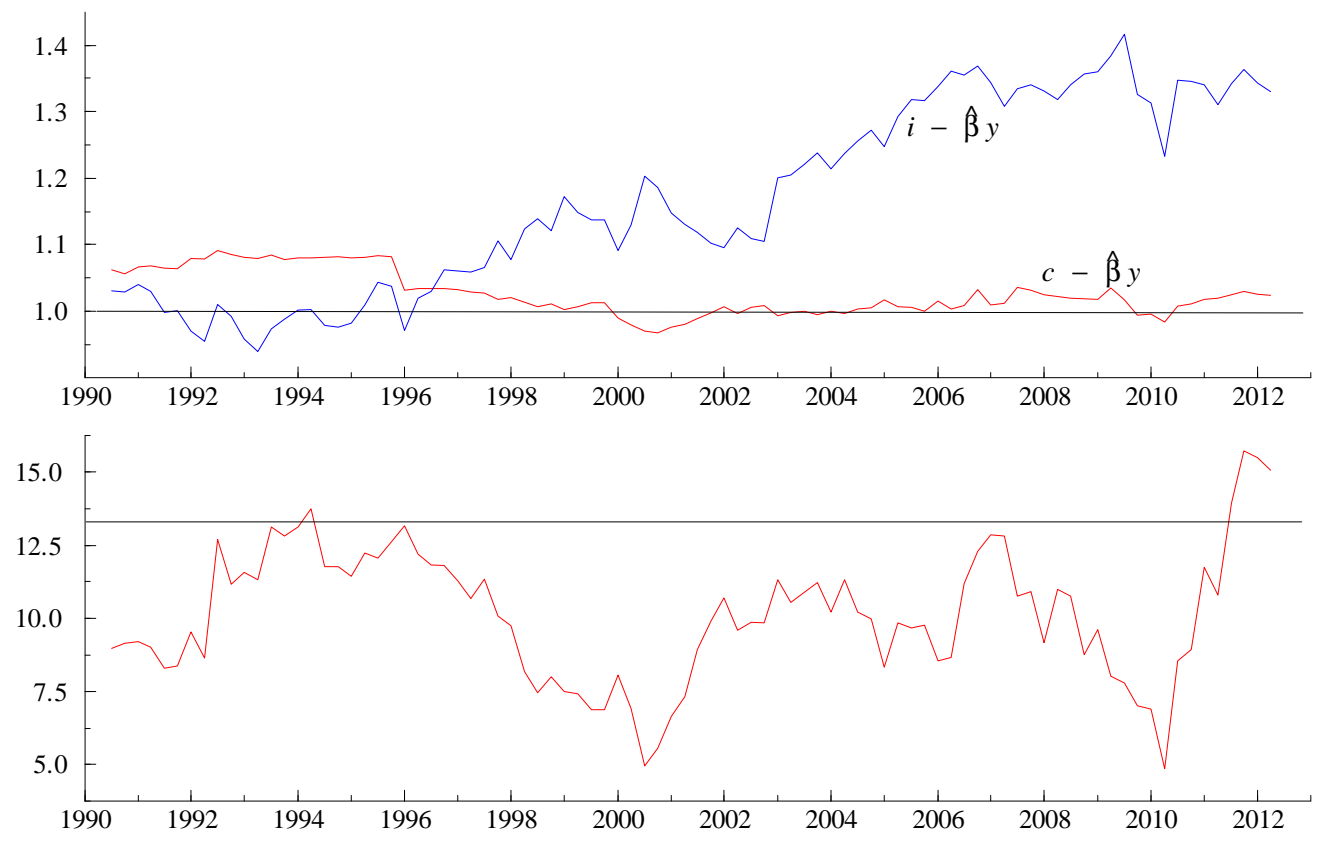

Figure 8: Top panel: Estimates of the long-run coefficients on $y$ in the $c-\beta y$ and $i-\beta y$ cointegrating vectors on samples of 100 observations ending at the data shown (less one period). The bottom panel reports the trace statistic for the null that the number of cointegrating vectors is less than or equal to 1, with the $10 \%$ (asymptotic) critical of 13.31 shown (taken from Johansen, 1995, Table 15.3). In all cases two lagged differences of the variables are included, as well as (an unrestricted) constant. 
Table 1: Description of Forecast Data and Real-Time Data

\begin{tabular}{lll}
\hline \hline Variable & SPF code & RTDSM code \\
\hline \hline Real GDP (GNP) & RGDP & ROUTPUT \\
Real federal government expenditure & RFEDGOV & - \\
Real state and local government expenditure & RSLGOV & - \\
Total government expenditure & - & RG \\
Real personal consumption & RCONSUM & RCON \\
Real nonresidential fixed investment & RNRESIN & RINVBF \\
Real residential fixed investment & RRESINV & RINVRESID
\end{tabular}

The SPF data were taken from the median levels database, downloaded from the Philadelphia Fed website (http://www.phil.frb.org/econ/spf/) on the 10th December 2013. We used the consumption series RCONSUM, for the investment series we used RNRESIN + RRESINV, and for output we used 'private' GDP defined as RGDP - RFEDGOV - RSLGOV.

The real-time data were downloaded from http://www.philadelphiafed.org/research-anddata/real-time-center/real-time-data/ on the 10th December 2013. The series were constructed as: consumption, RCON; investment, RINVBF + RINVRESID; and output as ROUTPUT - RG. The data consist of vintages from 1965Q4 to 2013Q4, inclusive, and generally include observations for the periods from 1947Q1 up to one observation before the vintage date. (An exception is that the 1996Q1 vintage observation for 1995Q4 is a missing value for all the national accounts series). We use the quarterly vintages of quarterly data (these have the suffix 'QvQd' on the website, e.g., 'ROUTPUT.QvQd').

Table 2: Means and standard deviations of growth rate forecasts by horizon

\begin{tabular}{llccccc|cccccc}
\hline & \multicolumn{9}{c|}{ 1990:Q3 to 2012:Q2 } & \multicolumn{5}{c}{ 1990:Q3 to 2005:Q4 } \\
\hline Horizon & & 0 & 1 & 2 & 3 & 4 & 0 & 1 & 2 & 3 & 4 \\
Output & Mean & 0.60 & 0.68 & 0.74 & 0.78 & 0.80 & 0.65 & 0.73 & 0.76 & 0.79 & 0.81 \\
& Std. & 0.49 & 0.32 & 0.20 & 0.19 & 0.14 & 0.41 & 0.27 & 0.20 & 0.19 & 0.16 \\
Consumption & & & & & & & & & & & \\
& Mean & 0.56 & 0.59 & 0.63 & 0.64 & 0.64 & 0.62 & 0.62 & 0.66 & 0.66 & 0.66 \\
& Std. & 0.33 & 0.23 & 0.15 & 0.12 & 0.12 & 0.29 & 0.21 & 0.13 & 0.12 & 0.12 \\
Investment & & & & & & & & & & & \\
& Mean & 0.74 & 0.88 & 1.06 & 1.11 & 1.15 & 1.01 & 1.05 & 1.13 & 1.12 & 1.12 \\
& Std. & 1.46 & 1.01 & 0.70 & 0.54 & 0.44 & 1.18 & 0.70 & 0.47 & 0.39 & 0.41 \\
\hline
\end{tabular}

The forecasts are of percentage growth rates. 
Table 3: Average changes in survey forecasts from imposing restrictions

\begin{tabular}{ll}
\hline Forecast of: & \\
log difference of consumption & 0.01 \\
$\log$ difference of investment & 0.41 \\
$\log$ difference of output 1 & 0.14 \\
$\log$ difference of output 2 & 0.10 \\
$\ln (\mathrm{c})-0.95^{*} \ln (\mathrm{y})$ & 0.13 \\
$\ln (\mathrm{i})-1.35^{*} \ln (\mathrm{y})$ & 0.27 \\
\hline
\end{tabular}

The table reports the average absolute difference between the reported and tilted $h=4$ forecasts. (All the forecasts/changes are multiplied by 100). Output 1 indicates the tilted output growth forecasts were obtained from a bivariate system consisting of consumption and output, and output 2 denotes the investment-output system.

Table 4: MSEs of SPF forecasts of growth rates

\begin{tabular}{lccccc|ccccc}
\hline & \multicolumn{4}{c|}{ 1990:Q3 to 2012:Q2 } & \multicolumn{5}{c}{ 1990:Q3 to 2005:Q4 } \\
Horizon & 0 & 1 & 2 & 3 & 4 & 0 & 1 & 2 & 3 & 4 \\
\hline Consumption & 0.18 & 0.23 & 0.22 & 0.24 & 0.25 & 0.21 & 0.24 & 0.23 & 0.22 & 0.23 \\
Investment & 2.52 & 3.78 & 4.82 & 4.91 & 5.39 & 1.65 & 2.54 & 2.86 & 2.70 & 2.99 \\
Output & 0.23 & 0.36 & 0.44 & 0.47 & 0.48 & 0.22 & 0.31 & 0.33 & 0.31 & 0.31 \\
\hline
\end{tabular}

The forecasts are of one hundred times the differences of the logs. 
Table 5: Relative accuracy of reported survey growth rate forecasts and exponentially-tilted survey forecasts

\begin{tabular}{lcc|cc}
\hline \multirow{2}{*}{ Horizon } & $3990: \mathrm{Q} 3$ to 2012:Q2 & \multicolumn{2}{c}{ 1990:Q3 to 2005:Q4 } \\
\hline \hline \multicolumn{5}{c}{ Panel A. MSEs of tilted forecasts of growth rates } \\
as ratios of reported forecasts: Bivariate systems \\
\hline Consumption & 0.99 & 1.00 & 1.00 & 1.00 \\
Investment $_{\text {Output }_{c}}$ & 1.15 & 1.05 & 1.08 & 1.04 \\
Output $_{i}$ & 0.98 & 0.98 & 1.06 & 1.05 \\
\hline \multicolumn{5}{c}{ Panel B. MSEs of tilted forecasts of growth rates } \\
as ratios of reported forecasts: Trivariate system \\
\hline Consumption & 1.08 & 1.03 & 1.08 \\
Investment & 1.15 & 1.06 & 1.15 & 1.03 \\
Output & 1.01 & 1.01 & 1.06 & 1.07 \\
\hline Panel C. MSEs of tilted forecasts of two-sector model combinations \\
\multicolumn{5}{c}{ of levels as ratios of reported forecasts } \\
\hline Consumption-Output & 1.03 & 0.94 & 1.02 & 0.93 \\
Investment-Output & 1.10 & 1.04 & 1.06 & 1.03 \\
\hline
\end{tabular}




\section{Appendices}

\subsection{Appendix A}

The tilted density is known to be multivariate normal when the base density is multivariate normal and the moment restrictions are linear. The new density can be written as:

$$
\begin{aligned}
h_{t}^{*}\left(y_{t+h}\right) & =\exp \left\{\eta_{t}+\xi_{t}^{\prime}\left[g\left(y_{t+h}-\widetilde{\mu}_{t+h}\right)\right]\right\} f_{t}\left(y_{t+h}\right) \\
& =(2 \pi)^{-\frac{N}{2}}\left|\Sigma_{t+h}\right|^{-\frac{1}{2}} \exp \left\{-\frac{1}{2}\left(y_{t+h}-\mu_{t+h}\right)^{\prime} \Sigma_{t+h}^{-1}\left(y_{t+h}-\mu_{t+h}\right)+\eta_{t}+\xi_{t}^{\prime} \beta^{\prime} y_{t+h}(\}\right)
\end{aligned}
$$

where the second line sets $f_{t}\left(y_{t+h}\right) \sim N\left(\mu_{t+h}, \Sigma_{t+h}\right)$ and $g\left(y_{t+h}-\widetilde{\mu}_{t+h}\right)=\beta^{\prime} y_{t+h}$. We write the exponent as:

$$
-\frac{1}{2}\left(y_{t+h}-\mu_{t+h}\right)^{\prime} \Sigma_{t+h}^{-1}\left(y_{t+h}-\mu_{t+h}\right)+\eta_{t}+\xi_{t}^{\prime} \beta^{\prime} y_{t+h}=y_{t+h}^{\prime} A y_{t+h}+y_{t+h}^{\prime} B+C
$$

where $A=-\frac{1}{2} \Sigma_{t+h}^{-1}, B=\Sigma_{t+h}^{-1} \mu_{t+h}+\beta \xi_{t}, C=-\frac{1}{2} \mu_{t+h}^{\prime} \Sigma_{t+h}^{-1} \mu_{t+h}+\eta_{t}$. Then completing the square we obtain:

$$
y_{t+h}^{\prime} A y_{t+h}+y_{t+h}^{\prime} B+C=\left(y_{t+h}+\frac{1}{2} A^{-1} B\right)^{\prime} A\left(y_{t+h}+\frac{1}{2} A^{-1} B\right)+\left[C-\frac{1}{4} B^{\prime} A^{-1} B\right] .
$$

Substituting in (7) gives:

$h_{t}^{*}\left(y_{t+h}\right)=(2 \pi)^{-\frac{N}{2}}\left|\Sigma_{t+h}\right|^{-\frac{1}{2}} \exp \left\{\left(y_{t+h}+\frac{1}{2} A^{-1} B\right)^{\prime} A\left(y_{t+h}+\frac{1}{2} A^{-1} B\right)+\left[C-\frac{1}{4} B^{\prime} A^{-1} B\right]\right\}$

From (8) it follows immediately that $E_{h^{*}}\left(y_{t+h}\right)=-\frac{1}{2} A^{-1} B$. Then the moment restrictions $E_{h^{*}}\left(\beta^{\prime} y_{t+h}\right)=0$ imply that $-\frac{1}{2} \beta^{\prime} A^{-1} B=0$, the solution to which implies:

$$
\xi_{t}=-\left(\beta^{\prime} \Sigma_{t+h} \beta\right)^{-1} \beta^{\prime} \mu_{t+h}
$$

and that:

$$
\mu^{*} \equiv E_{h^{*}}\left(y_{t+h}\right)=\mu_{t+h}-\Sigma_{t+h} \beta\left(\beta^{\prime} \Sigma_{t+h} \beta\right)^{-1} \beta^{\prime} \mu_{t+h} .
$$


Although not necessary to calculate $\mu^{*}$, we can solve for $\eta_{t}$ by setting $\left[C-\frac{1}{4} B^{\prime} A^{-1} B\right]=0$, which gives:

$$
\begin{aligned}
\eta_{t} & =-\xi_{t}^{\prime} \beta^{\prime} \mu_{t+h}-\frac{1}{2} \xi_{t}^{\prime} \beta^{\prime} \Sigma_{t+h} \beta \xi_{t} \\
& =\frac{1}{2} \mu_{t+h}^{\prime} \beta\left(\beta^{\prime} \Sigma_{t+h} \beta\right)^{-1} \beta^{\prime} \mu_{t+h}
\end{aligned}
$$

(where the second line substitutes for $\xi_{t}$ from (9)).

\subsection{Appendix B}

We establish that long-run relationships, in the form of cointegrating combinations of integrated variables, imply that long-horizon forecasts of growth rates satisfy certain restrictions.

Suppose we have an $n \times 1$ vector of time-series variables, then using a first-order dynamic linear system for convenience:

$$
x_{t}=\Upsilon x_{t-1}+\tau+v_{t},
$$

where $v_{t} \sim I N[0, \Omega]$ for $t=1,2, \ldots, T$. $\Upsilon$ is an $n \times n$ matrix of coefficients. In vector equilibrium-correction form we have:

$$
\Delta x_{t}=\Pi x_{t-1}+\tau+v_{t},
$$

where $\Pi=\Upsilon-I_{n}=\alpha \beta^{\prime}$ and $\alpha$ and $\beta$ are $n \times r$ of rank $r<n$ when $x_{t} \sim I(1)$ and the cointegrating rank is $r .{ }^{19}$

We can also write:

$$
z_{t}=G z_{t-1}+\Psi_{0} D_{t}+\epsilon_{t}
$$

where $z_{t}^{\prime}=\left(z_{a, t}: Z_{b, t}\right)=\left(x_{t}^{\prime} \beta: \Delta x_{b, t}^{\prime}\right)$, with $\beta$ normalized such that its first $r$ rows are the identity matrix, i.e., $\beta=\left(I_{r}: \beta_{2}^{\prime}\right)^{\prime}, \epsilon_{t} \sim I N_{n}[0, \Sigma]$. In (12), $\Delta x_{b, t}=J^{\prime} \Delta x_{t}$, and $\Psi_{0}=\left(\tau^{\prime} \beta\right.$ :

\footnotetext{
${ }^{19}$ In addition we assume that $\alpha_{\perp}^{\prime} \Theta \beta_{\perp}$ is full rank, where $\Theta$ is the mean-lag matrix (here, simply $\Upsilon$ ), and $\alpha_{\perp}$ and $\beta_{\perp}$ are full column rank $n \times(n-r)$ matrices such that $\alpha^{\prime} \alpha_{\perp}=\beta^{\prime} \beta_{\perp}=0$ (see Johansen (1992)).
} 
$\left.\tau_{b}^{\prime}\right)^{\prime}=Q \tau$, where $\tau_{b}=J^{\prime} \tau$ and $J^{\prime}=\left(0: I_{n-r}\right)$. In addition:

$$
Q=\left(\begin{array}{c}
\beta^{\prime} \\
J^{\prime}
\end{array}\right), G=\left(\begin{array}{cc}
\left(I_{r}+\beta^{\prime} \alpha\right) & 0 \\
\alpha_{b} & 0
\end{array}\right)=\left(\begin{array}{cc}
\lambda & 0 \\
\alpha_{b} & 0
\end{array}\right)
$$

and:

$$
\Sigma=\left(\begin{array}{cc}
\beta^{\prime} \Omega \beta & \beta^{\prime} \Omega J \\
J^{\prime} \Omega \beta & J^{\prime} \Omega J
\end{array}\right) .
$$

The system in (12) determines both the conditional and unconditional means and variances of all the $I(0)$ variables. For $\alpha \neq 0$, the long-run solution for the system is defined by:

$$
E\left[z_{t}\right]=\left(I_{n}-G\right)^{-1} Q \tau=\left(\begin{array}{c}
-\left(\beta^{\prime} \alpha\right)^{-1} \beta^{\prime} \tau \\
\alpha_{b}\left(\beta^{\prime} \alpha\right)^{-1} \beta^{\prime} \tau+\tau_{b}
\end{array}\right)
$$

Using (14) we can show that the expectation of $\Delta x_{t}$ is $E\left[\Delta x_{t}\right]=K \tau$, where $K=\left(I_{r}-\alpha\left(\beta^{\prime} \alpha\right)^{-1} \beta^{\prime}\right)$, so that $K \tau$ is the growth in the system, and $E\left[z_{a, t}\right]=-\left(\beta^{\prime} \alpha\right)^{-1} \beta^{\prime} \tau$ is given directly.

Then, letting $\widehat{x}_{T+h}$ denote the conditional $h$-step ahead expectation (of $T+h$ conditional on period $T$ ) we have:

$$
\widehat{x}_{T+h}=\Upsilon \widehat{x}_{T+h-1}+\tau,
$$

so that by backward substitution:

$$
\widehat{x}_{T+h}=\Upsilon^{h} x_{T}+\sum_{i=0}^{h-1} \Upsilon^{i} \tau
$$

and hence:

$$
\begin{aligned}
\hat{z}_{a, T+h} & \equiv \beta^{\prime} \widehat{x}_{T+h}=\beta^{\prime} \Upsilon^{h} x_{T}+\sum_{i=0}^{h-1} \beta^{\prime} \Upsilon^{i} \tau \\
& =\lambda^{h} z_{a, T}+\sum_{i=0}^{h-1} \lambda^{i} \beta^{\prime} \tau
\end{aligned}
$$


using $\beta^{\prime} \Upsilon^{i}=\lambda^{i} \beta .^{20}$ With $\hat{z}_{a, T+h-1}$ defined by substituting $h-1$ for $h$ in (15), we obtain:

$$
\begin{aligned}
\Delta \hat{z}_{a, T+h} & =\lambda^{h-1}(\lambda-1) z_{a, T}+\lambda^{h-1} \beta^{\prime} \tau \\
& =\lambda^{h-1} \beta^{\prime} \widehat{x}_{T+1} .
\end{aligned}
$$

Note $\lambda \rightarrow 0$ as $h \rightarrow \infty, \Delta \hat{z}_{a, T+h} \rightarrow 0$ as $h \rightarrow \infty$, and since $\Delta \hat{z}_{a, T+h}=\beta^{\prime} \Delta \widehat{x}_{T+h}$, we have established that the long-horizon growth rates satisfy the cointegrating combinations.

We have illustrated with the forecasts of growth rates from a correctly-specified system with the reduced-rank restriction imposed. But the forecasts from a VAR in differences, for example, will also satisfy the these restrictions, provided it is otherwise correctly-specified (see below).

\subsection{Appendix $\mathrm{C}$}

We show that MSE accuracy comparisons of forecasts from models with and without cointegrating relationships will only favour the former (at long horizons) when we evaluate forecasts of the cointegrating combination of the levels of the variables (as show by Clements and Hendry (1995)). This section draws on results in section 7.2.

Let the predictor that omits the cointegrating combinations be denoted by $\Delta \widetilde{x}_{T+h}$. Ignoring lags for simplicity, this predictor is:

$$
\Delta \widetilde{x}_{T+h}=K \tau
$$

so that the variables are forecast to increase at their (population) average growth rates, and so:

$$
\widetilde{x}_{T+h}=\widetilde{x}_{T+h-1}+K \tau=x_{T}+h K \tau .
$$

Hence $\beta^{\prime} \Delta \widetilde{x}_{T+h}=\beta^{\prime} K \tau=0$, so that the forecasts of the growth rates satisfy the cointegrating relations for all $h$.

The forecast of the cointegrating combination is then:

\footnotetext{
${ }^{20}$ Note that: $\beta^{\prime} \Upsilon^{i}=\left(\beta^{\prime}+\beta^{\prime} \alpha \beta^{\prime}\right) \Upsilon^{i-1}=\left(I_{r}+\beta^{\prime} \alpha\right) \beta^{\prime} \Upsilon^{i-1}=\lambda \beta^{\prime} \Upsilon^{i-1}=\cdots=\lambda^{i} \beta^{\prime}$, where $\lambda=\left(I_{r}+\beta^{\prime} \alpha\right)$.
} 


$$
\widetilde{z}_{a, T+h}=\beta^{\prime} \widetilde{x}_{T+h}=z_{a, T}+h \beta^{\prime} K \tau=z_{a, T} .
$$

Clements and Hendry (1995) show that the unconditional forecast-error variances of the correctlyspecified model, and of the model that omits the long-run information, will be the same as $h \rightarrow \infty$ when we evaluate forecasts of the differences / growth rates of the variables, but that the correctly-specified model will be more accurate for $z_{a, t}$. Some straightforward algebra establishes that the variances of the growth rate forecast errors differ by:

$$
\alpha \lambda^{h-1} V\left[z_{a T}\right] \lambda^{h-1 \prime} \alpha^{\prime}
$$

which goes to zero in $h$.

In terms of forecasting $z_{a, t}$, we can show that the unconditional variance of the correctlyspecified model is smaller by a positive definite matrix:

$$
\sum_{r=0}^{h-1} \sum_{q=0}^{h-1} \beta^{\prime} \alpha \lambda^{r} V\left[z_{a T}\right] \lambda^{q^{\prime}} \alpha^{\prime} \beta
$$

which does not disappear as $h$ gets large. In the bivariate case, $\lambda$ is a scalar, and (19) simplifies to:

$$
\left(\beta^{\prime} \alpha\right)^{2} V\left[z_{a T}\right]\left(\frac{1-\lambda^{h}}{1-\lambda}\right)^{2}
$$

indicating that the relative accuracy of the correctly-specified model is increasing in $h$. 